\title{
System Characterization Report on Resourcesat-2 Advanced Wide Field Sensor
}

Chapter $\mathrm{G}$ of

System Characterization of Earth Observation Sensors

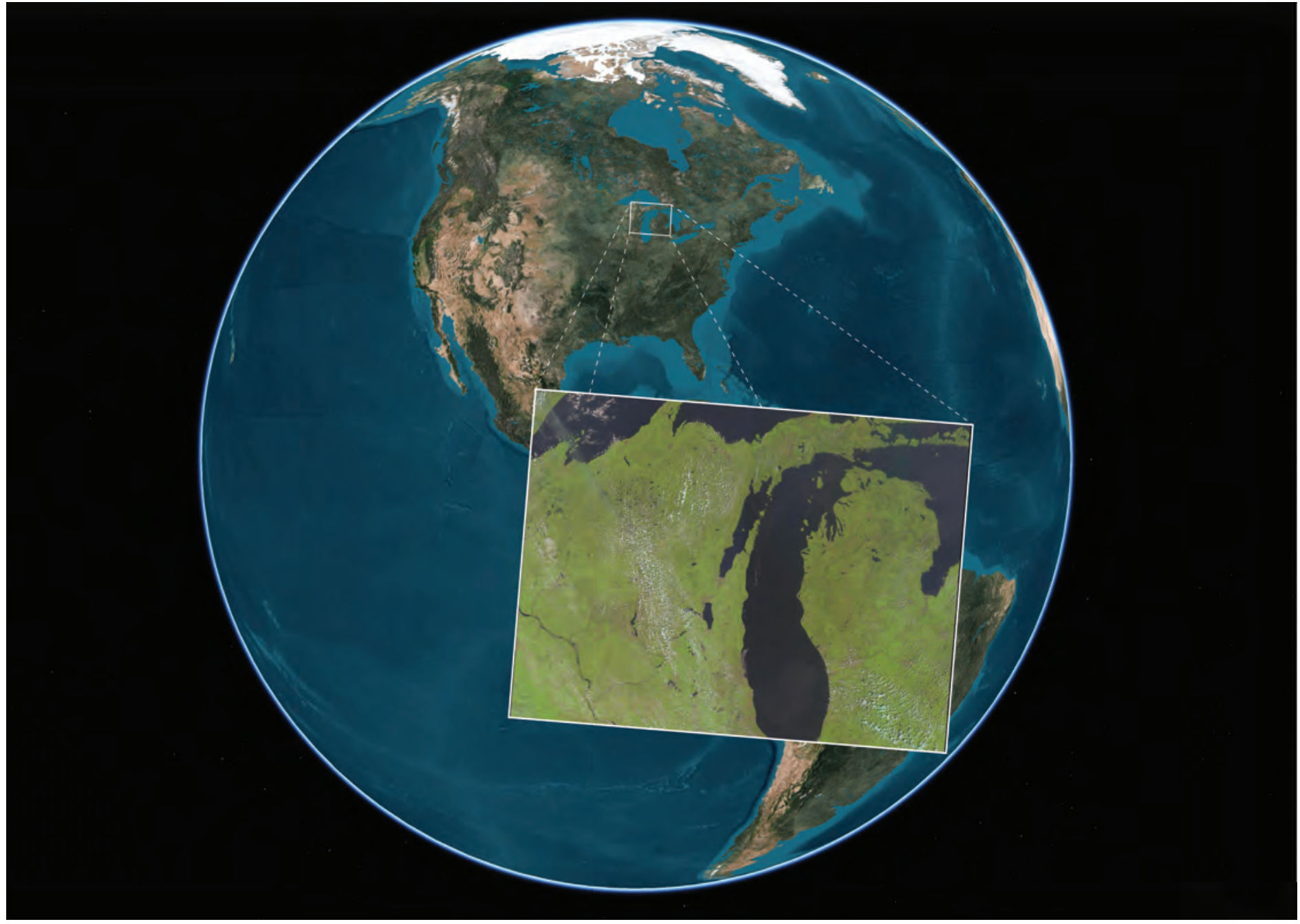

Open-File Report 2021-1030-G

Version 1.1, November 2021

U.S. Department of the Interior

U.S. Geological Survey 
Cover. Image of the Great Lakes captured by the Resourcesat-2 Advanced Wide Field Sensor. Image by the U.S. Geological Survey. Image of Earth from Analytical Graphics, Inc., Systems Tool Kit. 


\section{System Characterization Report on Resourcesat-2 Advanced Wide Field Sensor}

By Shankar N. Ramaseri Chandra, ${ }^{1}$ Minsu Kim, ${ }^{1}$ Jon Christopherson, ${ }^{1}$ Gregory L. Stensaas, ${ }^{2}$ and Cody Anderson ${ }^{2}$

Chapter $\mathrm{G}$ of

System Characterization of Earth Observation Sensors

Compiled by Shankar N. Ramaseri Chandra ${ }^{1}$

${ }^{1}$ KBR, Inc., under contract to the U.S. Geological Survey.

${ }^{2}$ U.S. Geological Survey.

Open-File Report 2021-1030-G

Version 1.1, November 2021 


\section{U.S. Geological Survey, Reston, Virginia: 2021 First release: 2021 \\ Revised: November 2021 (ver. 1.1)}

For more information on the USGS - the Federal source for science about the Earth, its natural and living resources, natural hazards, and the environment-visit https://www.usgs.gov or call 1-888-ASK-USGS.

For an overview of USGS information products, including maps, imagery, and publications, visit https://store.usgs.gov/.

Any use of trade, firm, or product names is for descriptive purposes only and does not imply endorsement by the U.S. Government.

Although this information product, for the most part, is in the public domain, it also may contain copyrighted materials as noted in the text. Permission to reproduce copyrighted items must be secured from the copyright owner.

Suggested citation:

Ramaseri Chandra, S.N., Kim, M., Christopherson, J., Stensaas, G.L., and Anderson, C., 2021, System characterization report on Resourcesat-2 Advanced Wide Field Sensor (ver. 1.1, November 2021), chap. G of Ramaseri Chandra, S.N., comp., System characterization of Earth observation sensors: U.S. Geological Survey Open-File Report 2021-1030, 22 p., https://doi.org/10.3133/ofr20211030G.

ISSN 2331-1258 (online) 


\section{Contents}

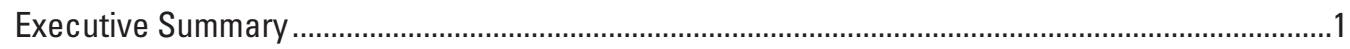

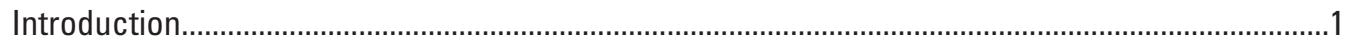

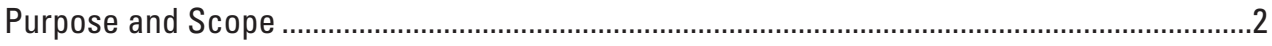

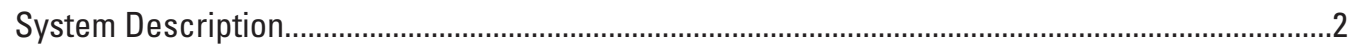

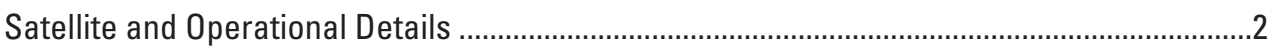

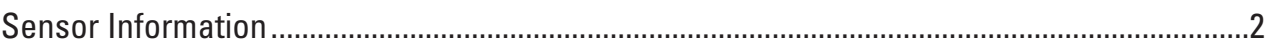

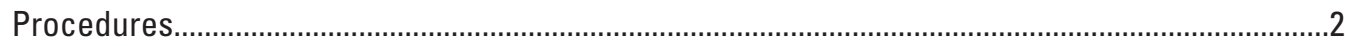

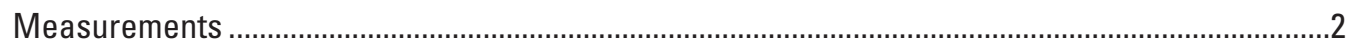

Analysis

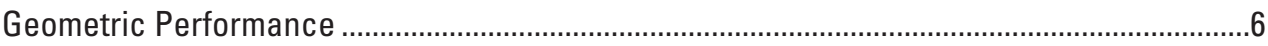

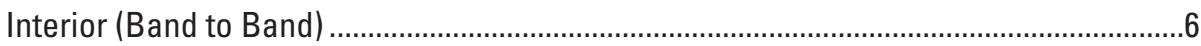

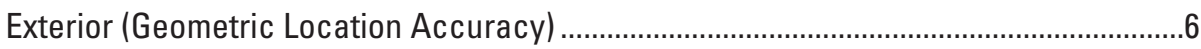

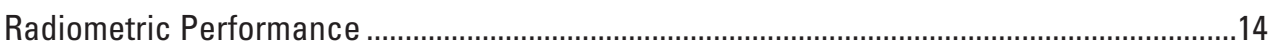

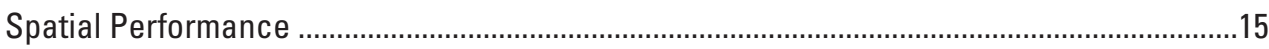

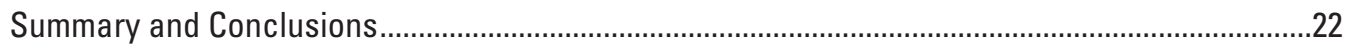

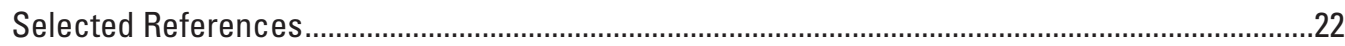

\section{Figures}

1. Graph showing Resourcesat-2 Advanced Wide Field Sensor relative spectral

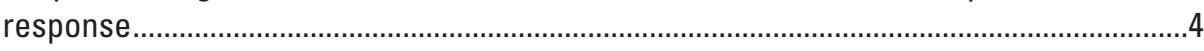

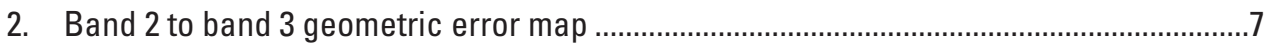

3. Band 2 to band 3 geometric error histogram and error distribution for Fargo,

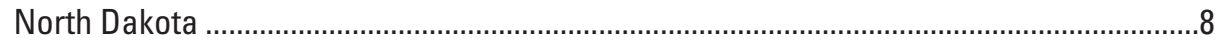

4. Band 3 to band 5 geometric error map ..................................................................

5. Band 3 to band 5 geometric error histogram and error distribution for Fargo,

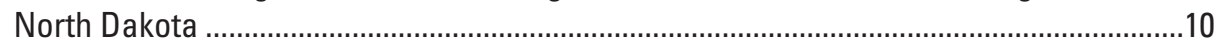

6. Map showing relative geometric error comparison for Landsat 8 Operational Land Imager and Resourcesat-2 Advanced Wide Field Sensor for Fargo,

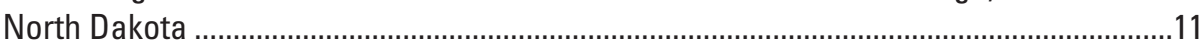

7. Relative geometric error histogram and error distribution for Fargo, North Dakota ......12

8. Map showing relative geometric error comparison for Landsat 80 perational Land Imager and Resourcesat-2 Advanced Wide Field Sensor for Colorado..................13

9. Relative geometric error histogram and error distribution for Colorado .........................14

10. Graphs showing Top of Atmosphere reflectance comparison for Landsat 8 Operational Land Imager and Resourcesat-2 Advanced Wide Field Sensor for

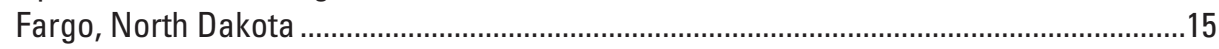

11. Resourcesat-2 Advanced Wide Field Sensor image region of interest selected for spatial analysis......................................................................................................... 17

12. Graphs showing band 2 raw edge transects and aligned transects ..............................17

13. Graphs showing band 2 edge spread function and line spread function and

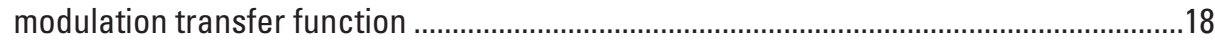

14. Graphs showing band 3 raw edge transects and aligned transects .............................18 
15. Graphs showing band 3 edge spread function and line spread function and modulation transfer function

16. Graphs showing band 4 raw edge transects and aligned transects

17. Graphs showing band 4 edge spread function and line spread function and modulation transfer function

18. Graphs showing band 5 raw edge transects and aligned transects

19. Graphs showing band 5 edge spread function and line spread function and modulation transfer function

\section{Tables}

1. Satellite and operational details for Resourcesat-2 Advanced Wide Field Sensor ..........3

2. Imaging sensor details for Resourcesat-2 Advanced Wide Field Sensor ..........................

3. U.S. Geological Survey measurement results .................................................................

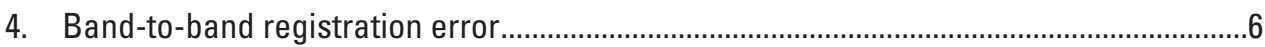

5. Geometric error of Resourcesat-2 Advanced Wide Field Sensor relative to Landsat 8 Operational Land Imager

6. Top of Atmosphere reflectance comparison of Resourcesat-2 Advanced Wide Field Sensor against Landsat 8 Operational Land Imager ...............................................16

7. Spatial performance of Resourcesat-2 Advanced Wide Field Sensor .............................16

\section{Conversion Factors}

International System of Units to U.S. customary units

\begin{tabular}{|c|c|c|}
\hline Multiply & By & To obtain \\
\hline \multicolumn{3}{|c|}{ Length } \\
\hline meter $(\mathrm{m})$ & 3.281 & foot $(\mathrm{ft})$ \\
\hline meter (m) & 1.094 & yard (yd) \\
\hline kilometer (km) & 0.6214 & mile (mi) \\
\hline
\end{tabular}

\section{Abbreviations}

$\begin{array}{ll}\text { AWiFS } & \text { Advanced Wide Field Sensor } \\ \text { ECCOE } & \text { EROS Cal/Val Center of Excellence } \\ \text { EROS } & \text { Earth Resources Observation and Science } \\ \text { EROSSC } & \text { EROS System Characterization } \\ \text { GSD } & \text { ground sample distance } \\ \text { JACIE } & \text { Joint Agency Commercial Imagery Evaluation } \\ \text { OLI } & \text { Operational Land Imager } \\ \text { RMSE } & \text { root mean square error } \\ \text { STDDEV } & \text { standard deviation } \\ \text { USGS } & \text { U.S. Geological Survey }\end{array}$




\title{
System Characterization Report on Resourcesat-2 Advanced Wide Field Sensor
}

\author{
By Shankar N. Ramaseri Chandra, ${ }^{1}$ Minsu Kim, ${ }^{1}$ Jon Christopherson, ${ }^{1}$ Gregory L. Stensaas, ${ }^{2}$ and Cody \\ Anderson 2
}

\section{Executive Summary}

This report addresses system characterization of the Indian Space Research Organisation Resourcesat-2 Advanced Wide Field Sensor (AWiFS) and is part of a series of system characterization reports produced and delivered by the U.S. Geological Survey Earth Resources Observation and Science Cal/Val Center of Excellence in 2021. These reports present and detail the methodology and procedures for characterization; present technical and operational information about the specific sensing system being evaluated; and provide a summary of test measurements, data retention practices, data analysis results, and conclusions.

Resourcesat-2 is a medium-resolution satellite launched in 2011 on the Polar Satellite Launch VehicleC16. Resourcesat- 2 carries the same sensing elements as Resourcesat-1 (launched in October 2003) and provides continuity for the mission. The objectives of the Resourcesat mission are to provide remote sensing data services to global users, focusing on data for integrated land and water resources management.

Resourcesat-2A is identical to Resourcesat-2 and was launched in 2016 on the Polar Satellite Launch VehicleC36 launch vehicle for continuity of data and improved temporal resolution. The two satellites operating in tandem improved the revisit capability from 5 days to $2-3$ days. The Resourcesat-2 platform is of Indian Remote Sensing Satellites1C/1D-P3 heritage and was built by the Indian Space Research Organisation. Resourcesat-2 and Resourcesat-2A carry the AWiFS, Linear Imaging Self Scanning-3, and Linear Imaging Self Scanning-4 sensors for medium-resolution imaging. More information on Indian Space Research Organisation satellites and sensors is available in the "2020 Joint Agency Commercial Imagery Evaluation-Remote Sensing Satellite Compendium" and from the manufacturer at https://www.isro.gov.in/.

The Earth Resources Observation and Science Cal/Val Center of Excellence system characterization team completed data analyses to characterize the geometric (interior and exterior), radiometric, and spatial performances. Results of these analyses indicate that AWiFS has an interior geometric performance in the range of $-16.080(-0.268$ pixel $)$ to 35.520 meters $(\mathrm{m} ; 0.592$ pixel) in easting and -25.680 $(-0.428$ pixel $)$ to $23.400 \mathrm{~m}$ ( 0.390 pixel $)$ in northing in band-to-band registration, an exterior geometric error of $-64.262(-1.071$ pixels $)$ to $-19.059 \mathrm{~m}(-0.318$ pixel $)$ in easting and $-29.028(-0.484$ pixel) to $41.249 \mathrm{~m}(0.687$ pixel $)$ in northing offset in comparison to the Landsat 8 Operational Land Imager, a radiometric performance in the range of $-0.065-0.083$ in offset and $0.652-1.056$ in slope, and a spatial performance in the range of 2.61-2.89 pixels for full width at half maximum, with a modulation transfer function at a Nyquist frequency in the range of 0.006-0.014.

\section{Introduction}

The Resourcesat-2 Advanced Wide Field Sensor (AWiFS) is a wide-angle medium-resolution camera consisting of four bands: green, red, near infrared, and shortwave infrared. The camera has a swath width of 740 kilometers, which enables AWiFS to provide a 5-day repeat capability. Resourcesat-2 was launched in 2011, and an identical mission, Resourcesat$2 \mathrm{~A}$, was launched in 2016. The primary objectives for data acquired by AWiFS include vegetation and crop monitoring, forest mapping, land cover/land use mapping, change detection, and regional resource assessment.

The data analysis results provided in this report have been derived from approved Joint Agency Commercial Imagery Evaluation (JACIE) processes and procedures. JACIE was formed to leverage resources from several Federal agencies for the characterization of remote sensing data and to share those results across the remote sensing community. More information about JACIE is available at https://www.usgs.gov/corescience-systems/eros/calval/jacie?qt-science_support_page_ related_con=3\#qt-science_support_page_related_con. 


\section{Purpose and Scope}

The purpose of this report is to describe the specific sensor or sensing system, test its performance in three categories, complete related data analyses to quantify these performances, and report the results in a standardized document. In this chapter, the AWiFS sensor is described. The performance of the system is limited to geometric, radiometric, and spatial analyses. The scope of the geometric assessment is limited to testing the interior alignments of spectral bands against each other and testing the exterior alignment in reference to the Landsat 8 Operational Land Imager (OLI).

The U.S. Geological Survey (USGS) Earth Resources Observation and Science (EROS) Cal/Val Center of Excellence (ECCOE) project, and the associated system characterization process used for this assessment, follows the USGS Fundamental Science Practices, which include maintaining data, information, and documentation needed to reproduce and validate the scientific analysis documented in this report. Additional information and guidance about Fundamental Science Practices and related resource information of interest to the public are available at https://www .usgs.gov/about/organization/science-support/office-sciencequality-and-integrity/fundamental-science-practices. For additional information related to the report, please contact ECCOE at eccoe@usgs.gov.

\section{System Description}

This section describes the satellite and operational details for Resourcesat-2 and provides information about the AWiFS.

\section{Satellite and Operational Details}

The satellite and operational details of Resourcesat-2 and information about the AWiFS are listed in table 1.

\section{Sensor Information}

The spectral characteristics and the relative spectral response of the AWiFS are listed in table 2 and figure 1, respectively.

\section{Procedures}

ECCOE has established standard processes to identify Earth observing systems of interest and to assess the geometric, radiometric, and spatial qualities of data products from these systems.

The assessment steps are as follows:

- system identification and investigation to learn the general specifications of the satellite and its sensor(s);

- data receipt and initial inspection to understand the characteristics and any overt flaws in the data product so that it may be further analyzed;

- geometry characterization, including interior geometric orientation measuring the relative alignment of spectral bands and exterior geometric orientation measuring how well the georeferenced pixels within the image are aligned to a known reference;

- radiometry characterization, including assessing how well the data product correlates with a known reference and, when possible, assessing the signal-to-noise ratio; and

- spatial characterization, assessing the two-dimensional fidelity of the image pixels to their projected ground sample distance (GSD).

Data analysis and test results are maintained at the USGS EROS Center by the ECCOE project.

\section{Measurements}

The observed USGS measurements are listed in table 3. The mean of interior (band-to-band) and exterior (image-toimage) mean errors, standard deviations (STDDEVs), and root mean square errors (RMSEs) are listed in meters (pixels). Details about the methodologies used are outlined in the "Analysis" section. 
Table 1. Satellite and operational details for Resourcesat-2 Advanced Wide Field Sensor.

[kg, kilogram; NIR, near infrared; SWIR, shortwave infrared; W, watt; AH, amp hour; Ni-Cd, nickel-cadmium; Mbps, megabit per second; , about; km, kilometer; ${ }^{\circ}$, degree; min, minute; \pm , plus or minus; lat., latitude; N/A, not applicable; m, meter; USGS, U.S. Geological Survey]

\begin{tabular}{|c|c|}
\hline Product information & Resourcesat-2 Advanced Wide Field Sensor data \\
\hline \multicolumn{2}{|r|}{ Satellite and operational information } \\
\hline Product name & Level 1T \\
\hline Satellite name & Resourcesat-2 \\
\hline Sensor name(s) & Advanced Wide Field Sensor \\
\hline Lift-off mass & $1,206 \mathrm{~kg}$ \\
\hline Instrument mass & $106 \mathrm{~kg}$ \\
\hline Sensor type & Multispectral, visible, and infrared (green, red, NIR, SWIR) \\
\hline Scanning technique & Pushbroom; 6,000 detectors array \\
\hline Power & Solar array generating $1,250 \mathrm{~W}$ at end of life; two $24 \mathrm{AH} \mathrm{Ni-Cd}$ batteries \\
\hline Data rate & $52.5 \mathrm{Mbps}$ \\
\hline Mission type & Global land-monitoring mission \\
\hline Launch date & April 20, 2011 \\
\hline Number of satellites & 2 \\
\hline Expected lifetime & $\sim 10$ years \\
\hline Operator & Indian Space Research Organisation \\
\hline \multicolumn{2}{|r|}{ Operational details } \\
\hline Operating orbit & Circular polar Sun synchronous \\
\hline Orbital altitude range & $817 \mathrm{~km}$ \\
\hline Sensor angle altitude & $98.7^{\circ}$ inclination \\
\hline Altitude and orbit control & Three-axis body stabilized using reaction wheels, magnetic torquers, and hydrazine thrusters \\
\hline Orbit period & $101.35 \mathrm{~min}$ \\
\hline Imaging time & 10:30 descending node \\
\hline Geographic coverage & Land imaging $\pm 81.3^{\circ}$ lat. \\
\hline Temporal resolution & 24 days \\
\hline Temporal coverage & 2011 to present \\
\hline Imaging angles & N/A \\
\hline Ground sample distance(s) & $56 \mathrm{~m}$ \\
\hline Data licensing & Free through USGS for the United States only \\
\hline Data pricing & Free through USGS for the United States only \\
\hline Product abstract & https://www.isro.gov.in/Spacecraft/resourcesat-2 \\
\hline Product locator & https://earthexplorer.usgs.gov/ \\
\hline
\end{tabular}


Table 2. Imaging sensor details for Resourcesat-2 Advanced Wide Field Sensor.

[The Resourcesat-2 Advanced Wide Field Sensor (AWiFS) has a swath width of 740 kilometers; $\mu \mathrm{m}$, micrometer; m, meter; NIR, near infrared; SWIR, shortwave infrared]

\begin{tabular}{|c|c|c|c|c|}
\hline \multirow[b]{2}{*}{ Spectral band(s) details } & \multicolumn{4}{|c|}{ Resourcesat-2 AWiFS } \\
\hline & $\begin{array}{l}\text { Lower band } \\
\qquad(\mu \mathrm{m})\end{array}$ & $\begin{array}{l}\text { Upper band } \\
(\mu \mathrm{m})\end{array}$ & $\begin{array}{c}\text { Radiometric } \\
\text { resolution } \\
\text { (bits) }\end{array}$ & $\begin{array}{l}\text { Ground sample } \\
\text { distance } \\
\text { (m) }\end{array}$ \\
\hline Band 2-green & 0.52 & 0.59 & 10 & 56 \\
\hline Band 3-red & 0.62 & 0.68 & 10 & 56 \\
\hline Band $4-\mathrm{NIR}$ & 0.77 & 0.86 & 10 & 56 \\
\hline
\end{tabular}

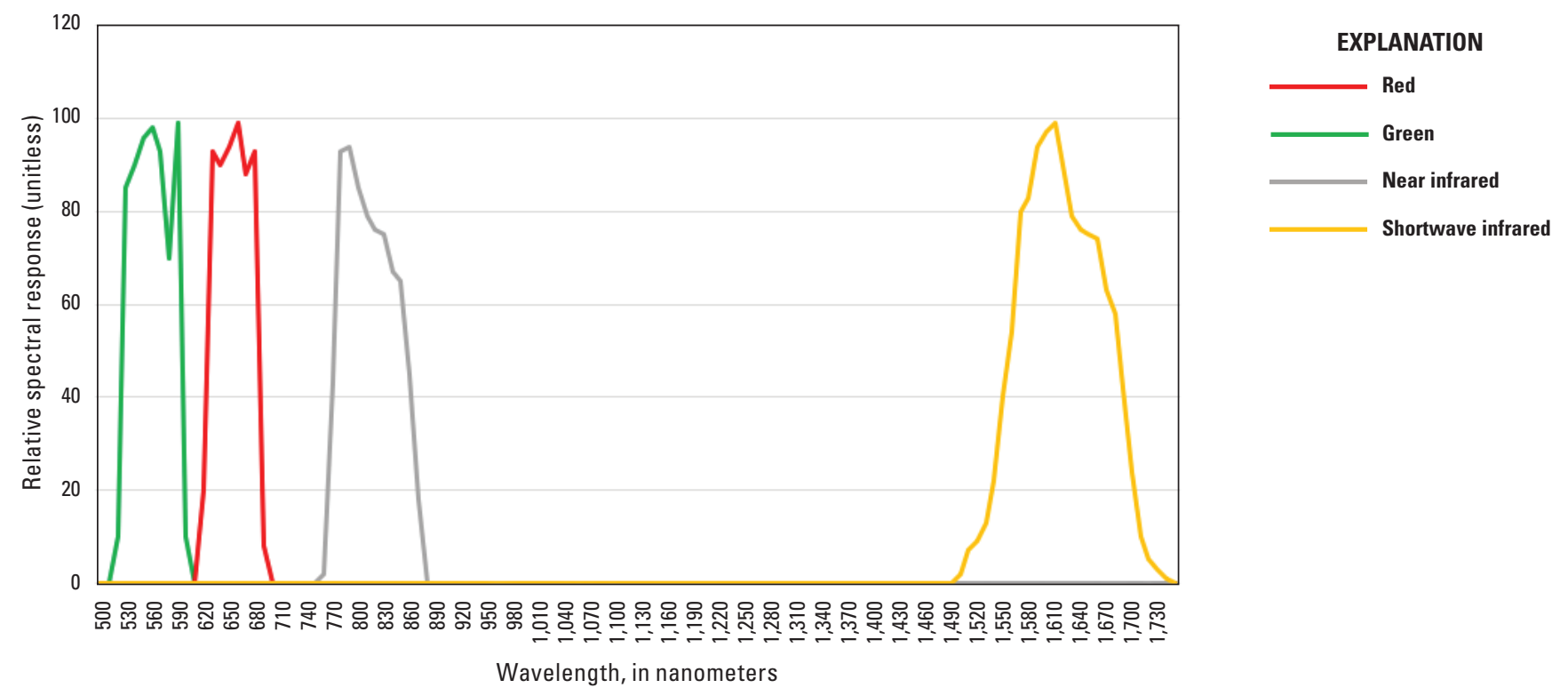

Figure 1. Resourcesat-2 Advanced Wide Field Sensor relative spectral response. 
Table 3. U.S. Geological Survey measurement results.

[USGS, U.S. Geological Survey; STDDEV, standard deviation; RMSE, root mean square error; NIR, near infrared; SWIR, shortwave infrared; AWiFS, Advanced Wide Field Sensor; L8 OLI, Landsat 8 Operational Land Imager; FWHM, full width at half maximum; MTF, modulation transfer function]

\begin{tabular}{|c|c|}
\hline Description of product & Top of Atmosphere reflectance \\
\hline \multicolumn{2}{|r|}{ USGS measurement results } \\
\hline \multicolumn{2}{|r|}{ Geometric performance (easting, northing), in meters (pixels) } \\
\hline Interior (band to band) & $\begin{array}{l}\text { Band } 2 \text { (green) } \\
\text { Mean: }-9.480 \text { to } 35.520 \mathrm{~m}(-0.158 \text { to } 0.592),-25.680 \text { to }-1.860 \mathrm{~m}(-0.428 \text { to }-0.031) \\
\text { RMSE: } 5.400 \text { to } 39.180 \mathrm{~m}(0.090 \text { to } 0.653), 4.980 \text { to } 41.460 \mathrm{~m}(0.083 \text { to } 0.691) \\
\text { Band } 3 \text { (red) } \\
\text { Mean: }-12.660 \text { to } 25.440 \mathrm{~m}(-0.211 \text { to } 0.424),-17.760 \text { to } 11.400 \mathrm{~m}(-0.296 \text { to } 0.190) \\
\text { RMSE: } 5.400 \text { to } 31.800 \mathrm{~m}(0.090 \text { to } 0.530), 4.980 \text { to } 29.040 \mathrm{~m}(0.083 \text { to } 0.484) \\
\text { Band } 4 \text { (NIR) } \\
\text { Mean: }-16.080 \text { to } 35.520 \mathrm{~m}(-0.268 \text { to } 0.592),-25.680 \text { to } 23.400 \mathrm{~m}(-0.428 \text { to } 0.390) \\
\text { RMSE: } 8.400 \text { to } 39.180 \mathrm{~m}(0.140 \text { to } 0.653), 10.560 \text { to } 41.460 \mathrm{~m}(0.176 \text { to } 0.691) \\
\text { Band 5 (SWIR) } \\
\text { Mean: }-16.080 \text { to } 11.520 \mathrm{~m}(-0.268 \text { to } 0.192),-15.660 \text { to } 23.400 \mathrm{~m}(-0.261 \text { to } 0.390) \\
\text { RMSE: } 8.340 \text { to } 20.340 \mathrm{~m}(0.139 \text { to } 0.339), 9.720 \text { to } 32.460 \mathrm{~m}(0.162 \text { to } 0.541)\end{array}$ \\
\hline Exterior (geometric location accuracy) & $\begin{array}{l}\text { Mean: }-64.262 \text { to }-19.059 \mathrm{~m}(-1.071 \text { to }-0.318),-29.028 \text { to } 41.249 \mathrm{~m}(-0.484 \text { to } 0.687) \\
\text { RMSE: } 0.363 \text { to } 1.289 \mathrm{~m}(21.755 \text { to } 77.325), 0.553 \text { to } 0.759 \mathrm{~m}(33.175 \text { to } 45.547)\end{array}$ \\
\hline \multicolumn{2}{|r|}{ Radiometric performance (offset, slope) } \\
\hline $\begin{array}{l}\text { Radiometric evaluation (linear regression-AWiFS versus } \\
\text { L8 OLI reflectance) }\end{array}$ & $\begin{array}{l}\text { Band 2-green (offset, slope): }(0.043 \text { to } 0.065,0.746 \text { to } 0.907) \\
\text { Band 3-red (offset, slope): }(0.031 \text { to } 0.065,0.741 \text { to } 0.886) \\
\text { Band 4-NIR (offset, slope): }(0.021 \text { to } 0.083,0.708 \text { to } 0.912) \\
\text { Band 5-SWIR (offset, slope): }(-0.065 \text { to } 0.042,0.652 \text { to } 1.056)\end{array}$ \\
\hline \multicolumn{2}{|r|}{ Spatial performance } \\
\hline Spatial performance measurement & $\begin{array}{l}\text { Band 2-green: } F W H M=2.61 \text { pixels; } \text { MTF at Nyquist }=0.014 \\
\text { Band 3-red: } F W H M=2.65 \text { pixels; MTF at Nyquist }=0.006 \\
\text { Band 4-NIR: FWHM }=2.89 \text { pixels; MTF at Nyquist }=0.008 \\
\text { Band 5-SWIR: } \text { FWHM }=2.85 \text { pixels; MTF at Nyquist }=0.011\end{array}$ \\
\hline
\end{tabular}




\section{Analysis}

This section describes the geometric, radiometric, and spatial performance of AWiFS.

\section{Geometric Performance}

The geometric performance for AWiFS is characterized in terms of the interior (band-to-band alignment) and exterior (geometric location accuracy) geometric analysis results.

\section{Interior (Band to Band)}

The band-to-band alignment analysis was completed using the EROS System Characterization (EROSSC) software on three separate images over the United States. Band combinations were registered against each other to determine the mean error, STDDEV, and RMSE as listed in table 4 with results represented in pixels at a 60-meter (m) GSD (the AWiFS image was resampled to $60 \mathrm{~m}$ ). The geometric error map comparing band 1 to band 2 over the Fargo, North Dakota, image, and the corresponding histogram graphs, are shown in figures $2-5$. The geometric error maps indicate the directional shift and relative magnitude of the shift, and the band-to-band error within the image is indicated by the histogram and the error distribution. Together, the interior and exterior geometric analysis results, as reported in the "Interior (Band to Band)" and "Exterior (Geometric Location Accuracy)" sections, provide a comprehensive assessment of geometric accuracy.

\section{Exterior (Geometric Location Accuracy)}

For this analysis, band 2 (green) of the AWiFS data was compared against the corresponding band from the Landsat 8 OLI image over two near-coincident images using the EROSSC software. Conjugate points in the reference and search images were identified automatically and refined using similarity measures such as normalized cross-correlation metrics, and the mean error, STDDEV, and RMSE results are listed in table 5 with results represented in pixels and meters at a 60-m GSD (OLI and AWiFS images were resampled to $60 \mathrm{~m}$ ). A geometric error map showing the directional shift and relative magnitude of the shift, when compared with Landsat 8 OLI, along with the corresponding histogram and error distribution, are provided in figures 6-9. The Landsat 8 OLI imagery had a control uncertainty of about $8 \mathrm{~m}$.

Table 4. Band-to-band registration error (in pixels).

[ID, identifier; STDDEV, standard deviation; RMSE, root mean square error]

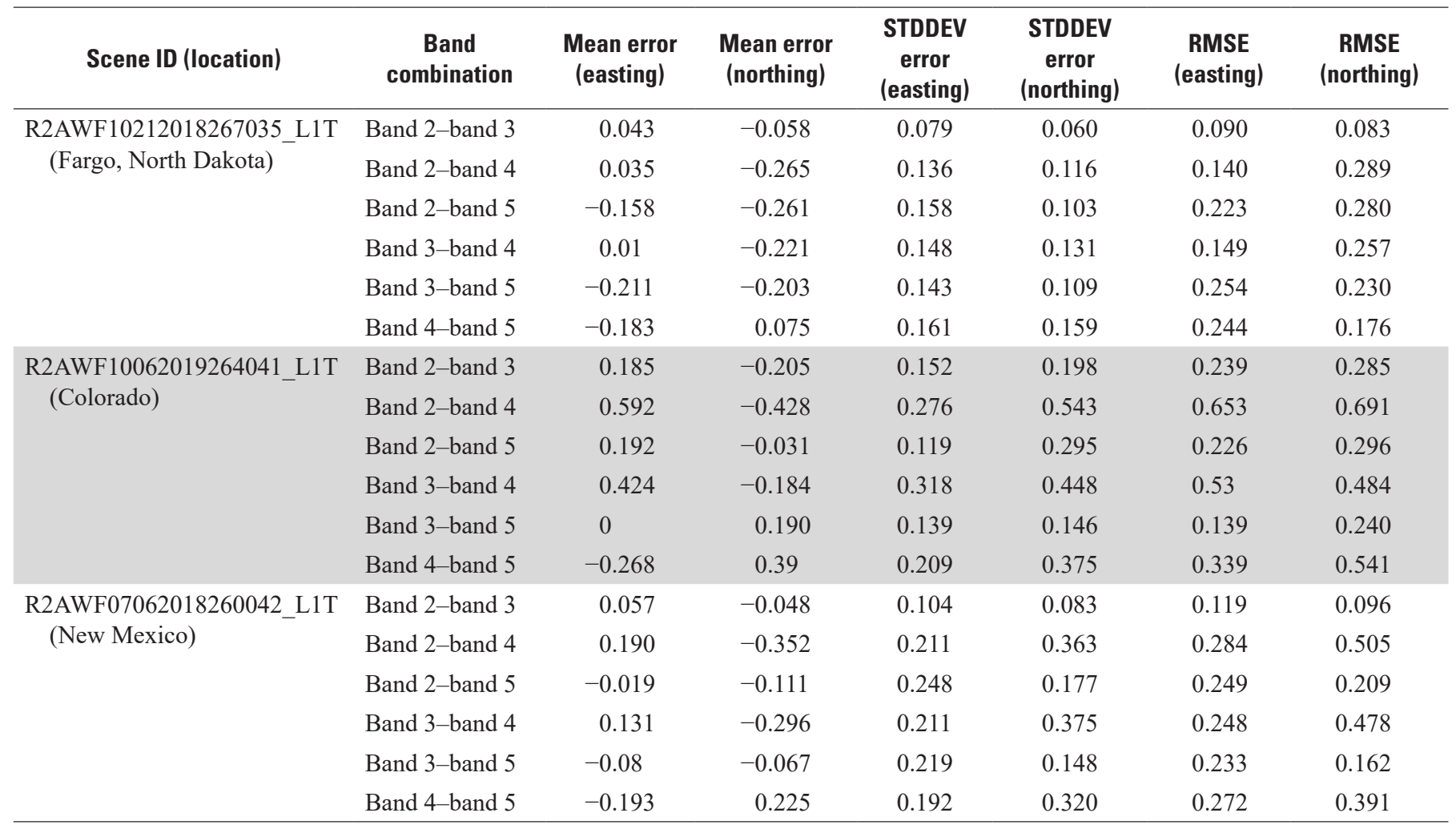




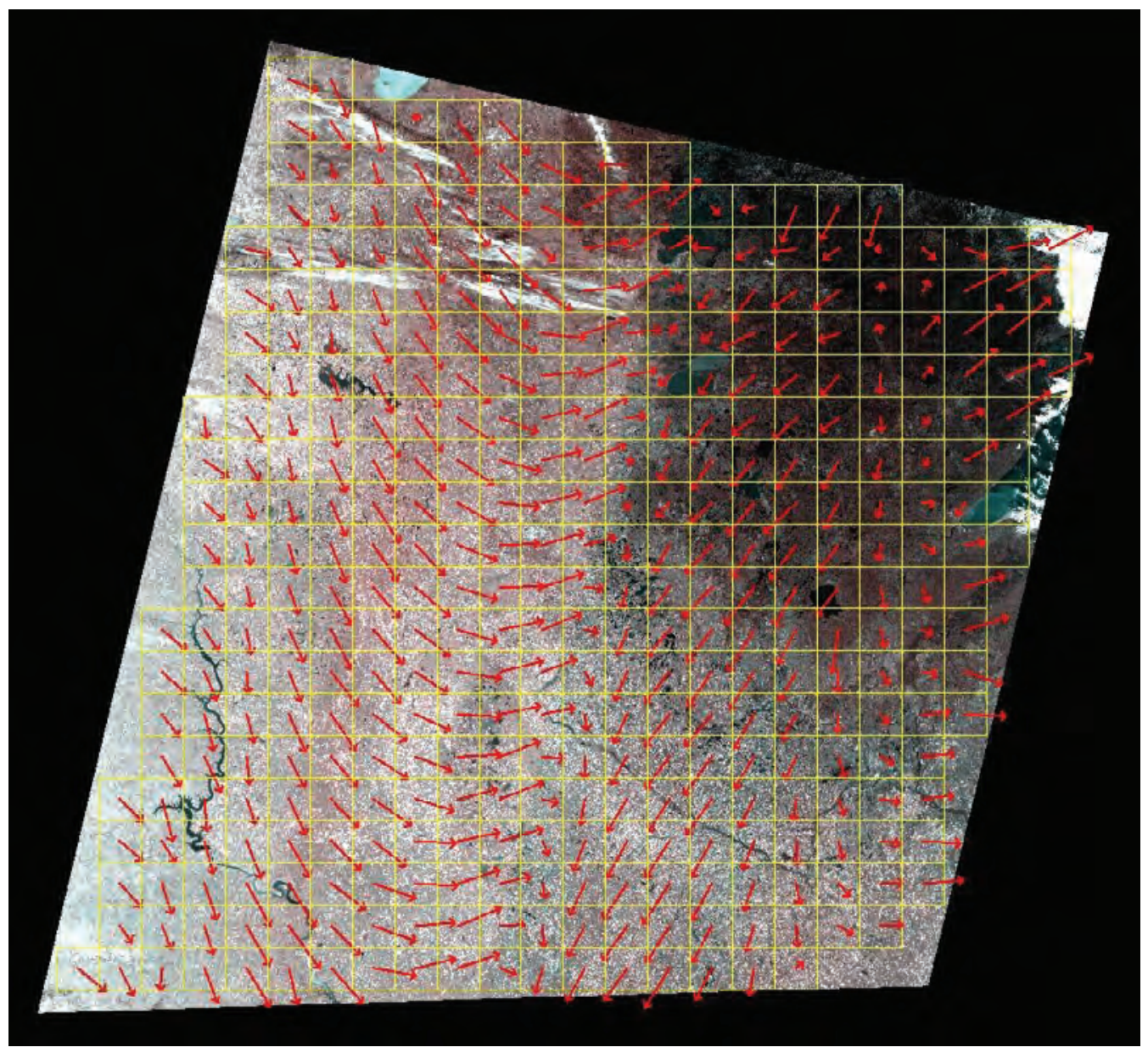

EXPLANATION

$\longrightarrow$ Easting and northing error Grid

Figure 2. Band 2 (green) to band 3 (red) geometric error map (Fargo, North Dakota). 

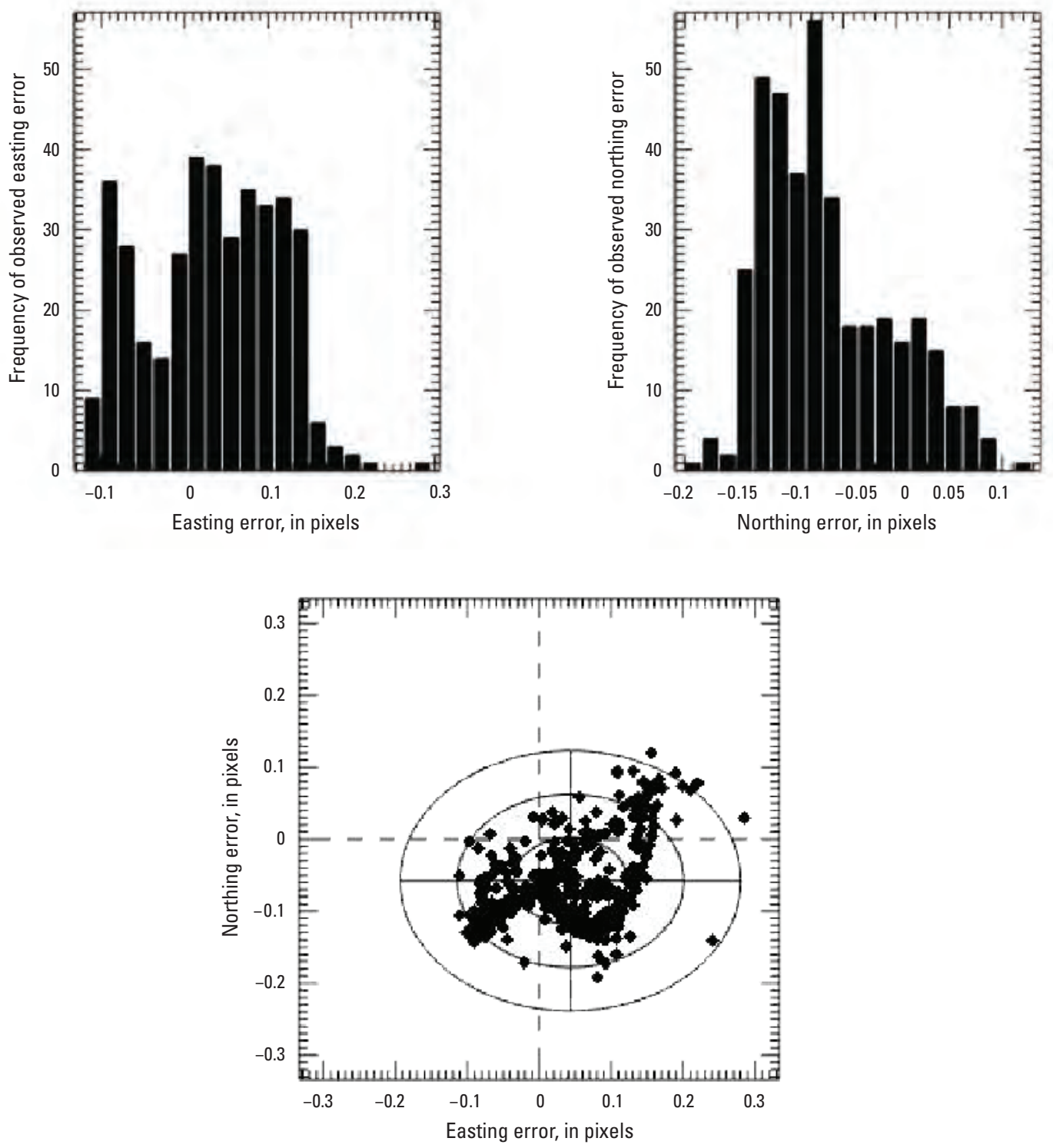

Figure 3. Band 2 (green) to band 3 (red) geometric error histogram (upper) and error distribution (lower) for Fargo, North Dakota. 


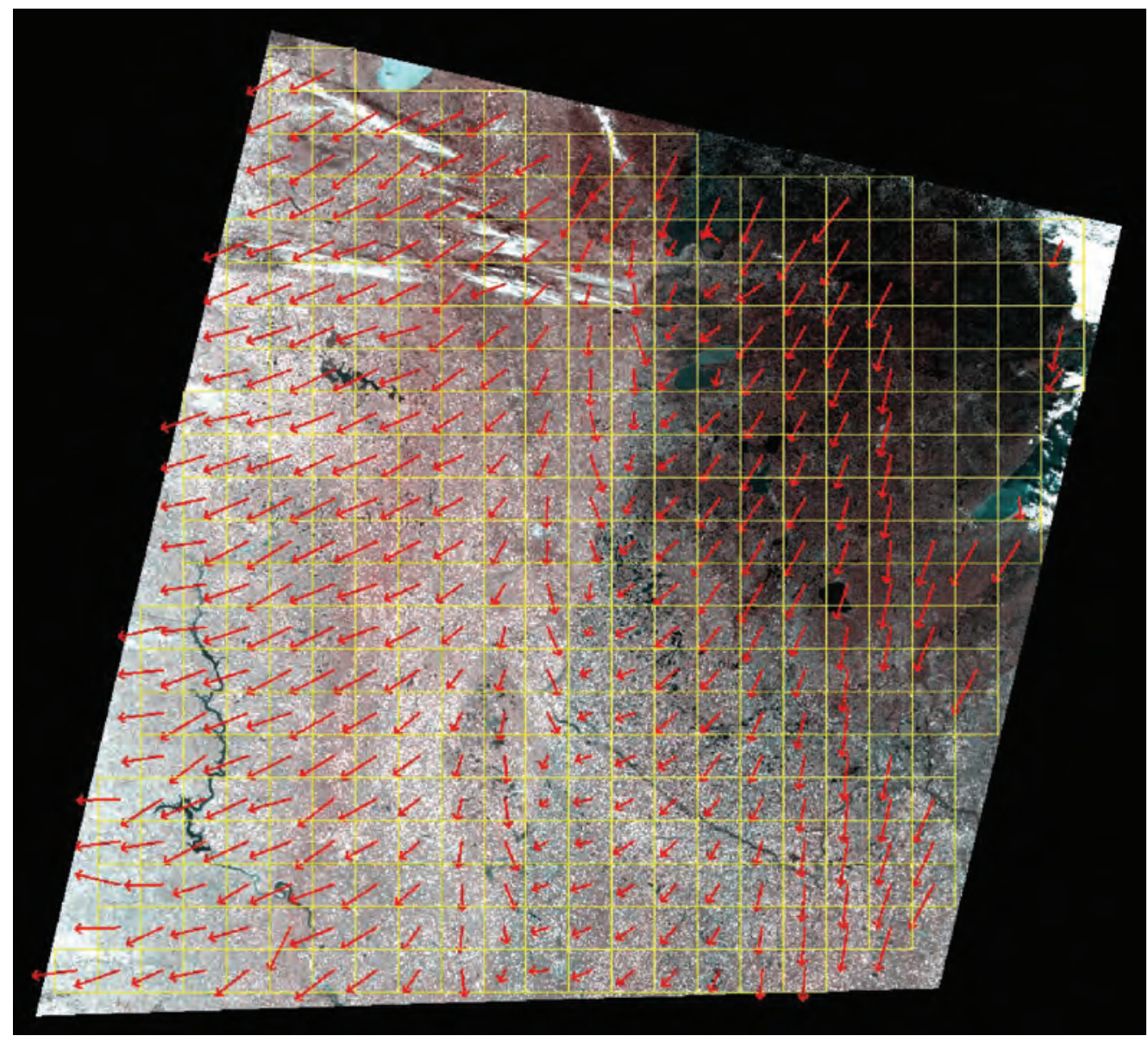

\section{EXPLANATION}

$\longrightarrow$ Easting and northing error Grid

Figure 4. Band 3 (red) to band 5 (shortwave infrared) geometric error map (Fargo, North Dakota). 

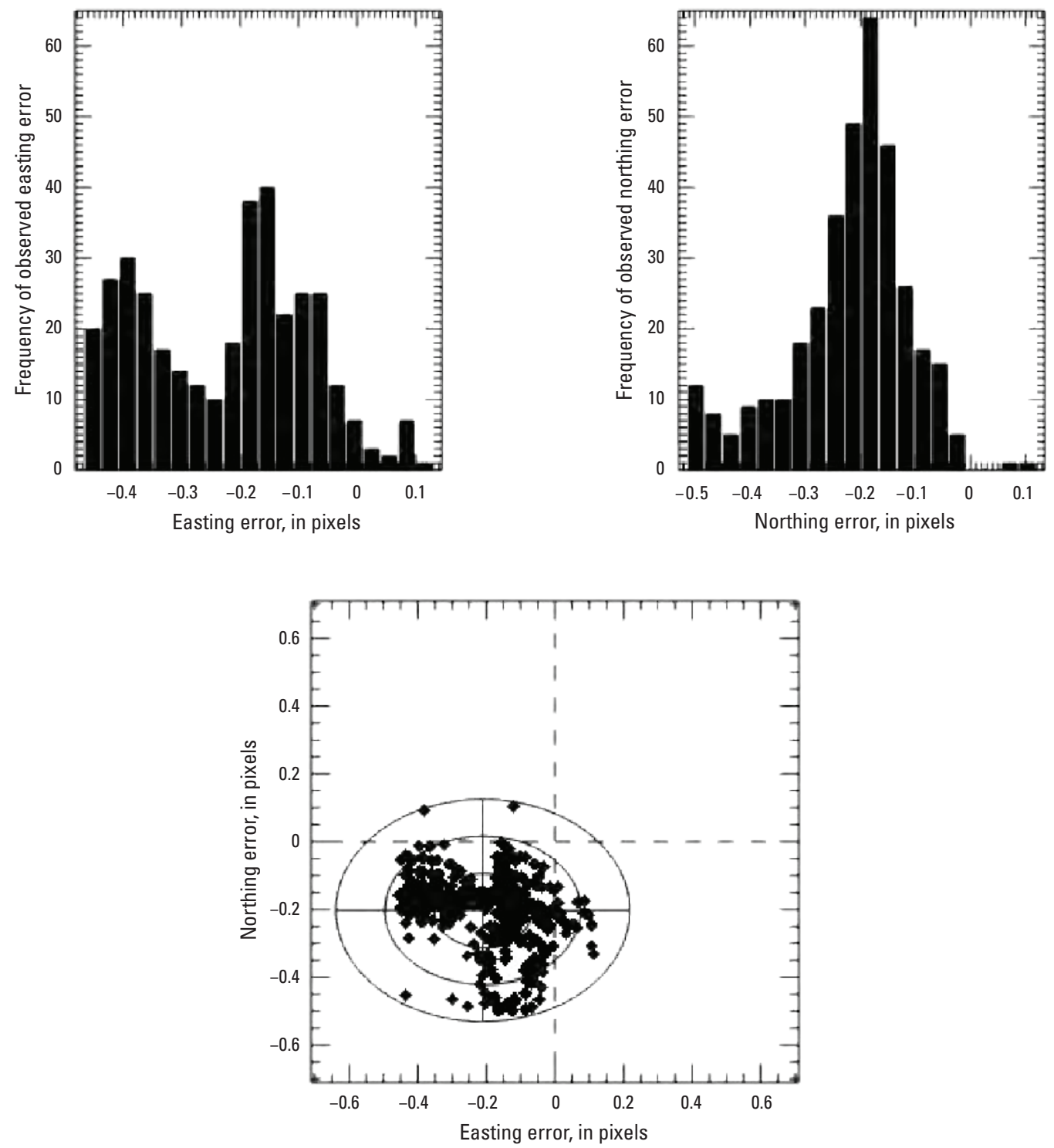

Figure 5. Band 3 (red) to band 5 (shortwave infrared) geometric error histogram (upper) and error distribution (lower) for Fargo, North Dakota. 
Table 5. Geometric error of Resourcesat-2 Advanced Wide Field Sensor relative to Landsat 8 Operational Land Imager.

[ID, identifier; STDDEV, standard deviation; RMSE, root mean square error]

\begin{tabular}{|c|c|c|c|c|c|c|c|}
\hline Scene ID & Unit & $\begin{array}{c}\text { Mean error } \\
\text { (easting) }\end{array}$ & $\begin{array}{l}\text { Mean error } \\
\text { (northing) }\end{array}$ & $\begin{array}{c}\text { STDDEV } \\
\text { error } \\
\text { (easting) }\end{array}$ & $\begin{array}{c}\text { STDDEV } \\
\text { error } \\
\text { (northing) }\end{array}$ & $\begin{array}{c}\text { RMSE } \\
\text { error } \\
\text { (easting) }\end{array}$ & $\begin{array}{c}\text { RMSE } \\
\text { error } \\
\text { (northing) }\end{array}$ \\
\hline \multirow{2}{*}{$\begin{array}{l}\text { R2AWF10212018267035_L1T } \\
\text { LC08_L1TP_030027_20181021_202 } \\
\text { 00830_02_T1 } \\
\text { (Fargo, North Dakota) }\end{array}$} & Pixels & -0.318 & -0.484 & 0.175 & 0.268 & 0.363 & 0.553 \\
\hline & Meters & -19.059 & -29.028 & 10.514 & 16.097 & 21.755 & 33.175 \\
\hline \multirow{2}{*}{$\begin{array}{l}\text { R2AWF10062019264041_L1T } \\
\text { LC08_L1TP_032034_20191006_202 } \\
\text { 00825_02_T1 } \\
\text { (Colorado) }\end{array}$} & Pixels & -1.071 & 0.671 & 0.719 & 0.289 & 1.289 & 0.730 \\
\hline & Meters & -64.262 & 40.247 & 43.166 & 17.355 & 77.325 & 43.804 \\
\hline \multirow{2}{*}{$\begin{array}{l}\text { R2AWF07062018260042_L1T } \\
\text { LC08_L1TP_033032_20180706_202 } \\
\text { 00831_02_T1 } \\
\text { (New Mexico) }\end{array}$} & Pixels & -0.596 & 0.687 & 0.325 & 0.323 & 0.678 & 0.759 \\
\hline & Meters & -35.744 & 41.249 & 19.529 & 19.409 & 40.684 & 45.547 \\
\hline
\end{tabular}

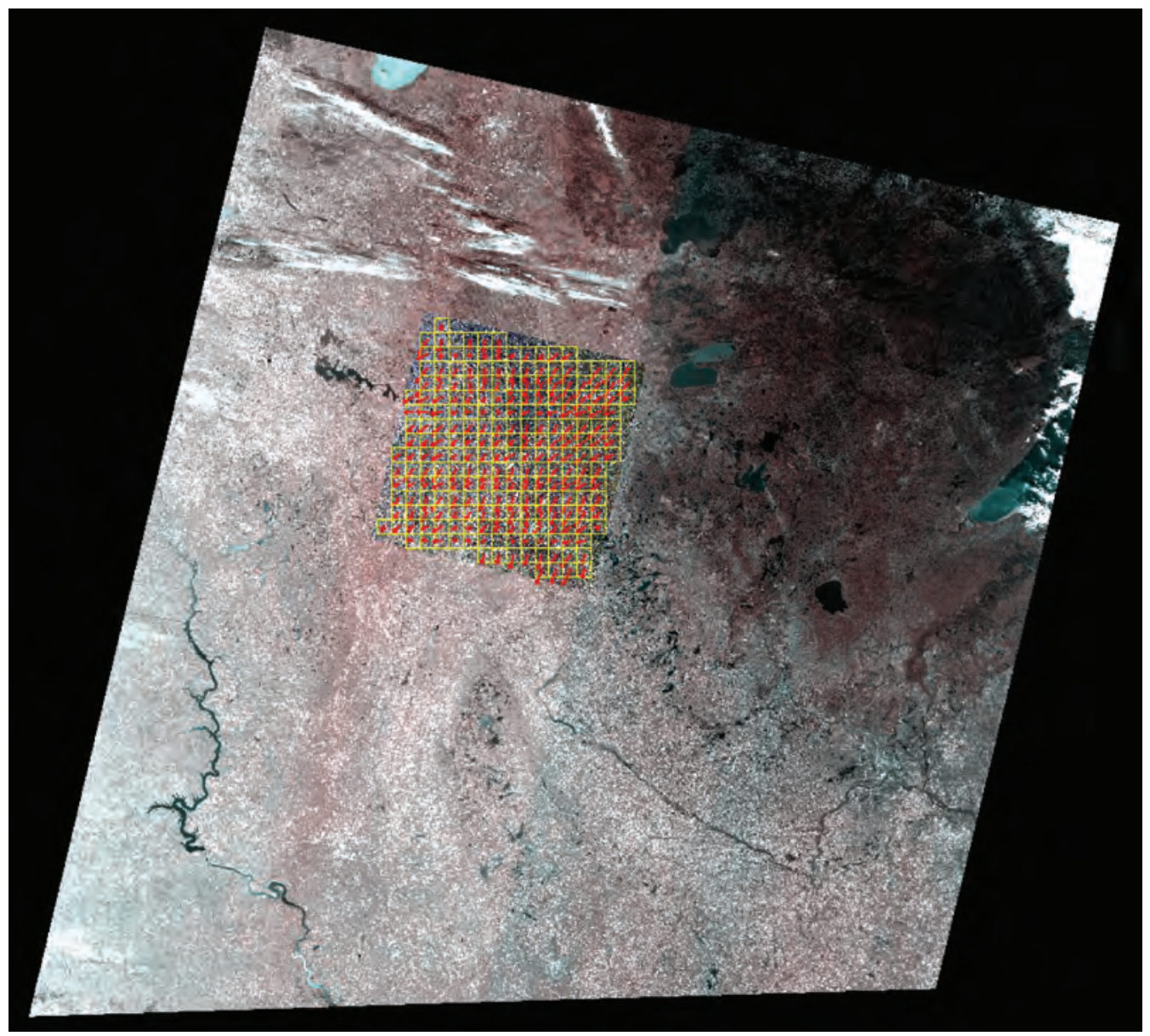

\section{EXPLANATION}

$\longrightarrow$ Easting and northing error Grid

Figure 6. Relative geometric error comparison for Landsat 8 Operational Land Imager and Resourcesat-2 Advanced Wide Field Sensor for Fargo, North Dakota. 

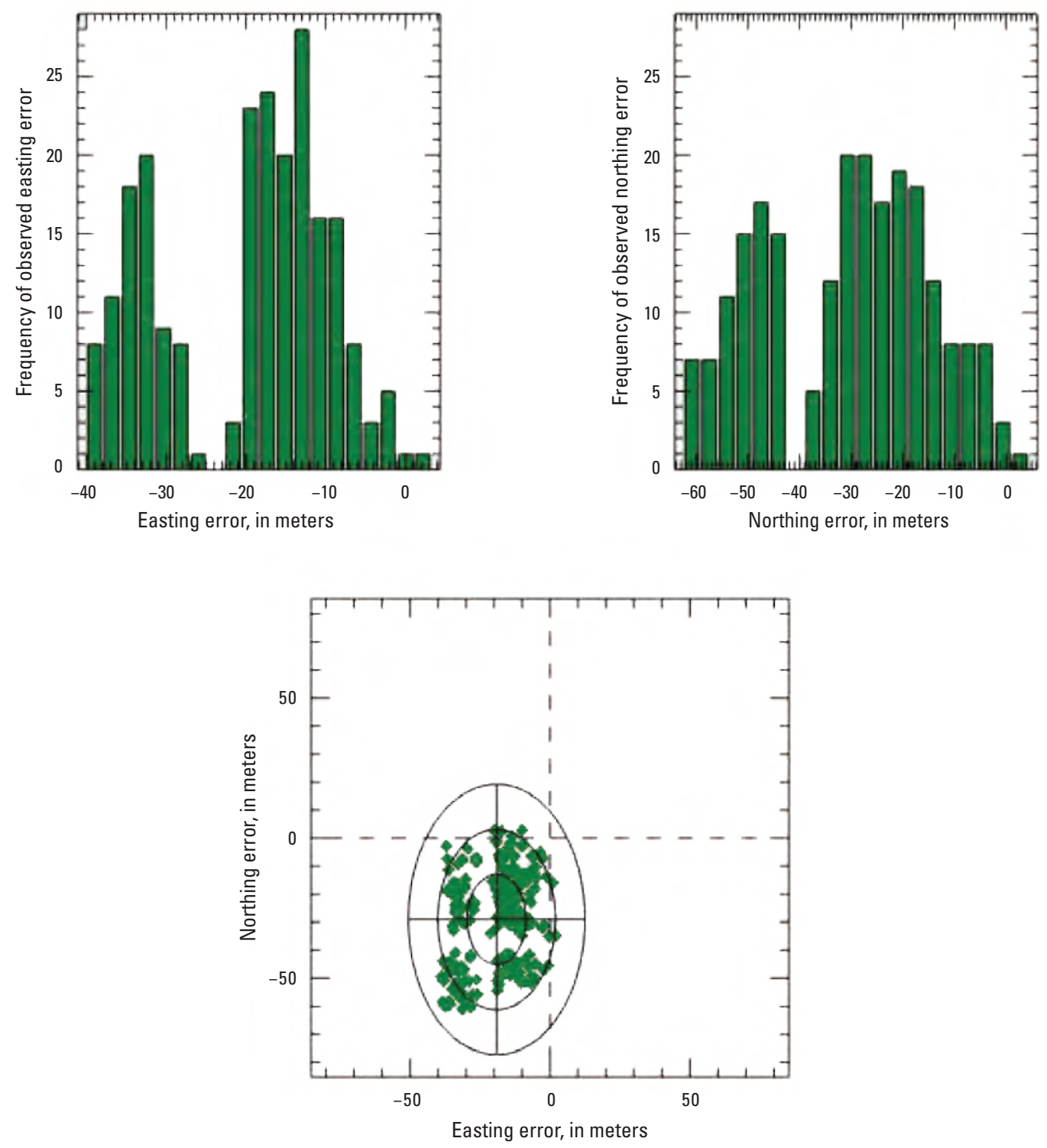

Figure 7. Relative geometric error histogram (upper) and error distribution (lower) for Fargo, North Dakota. 


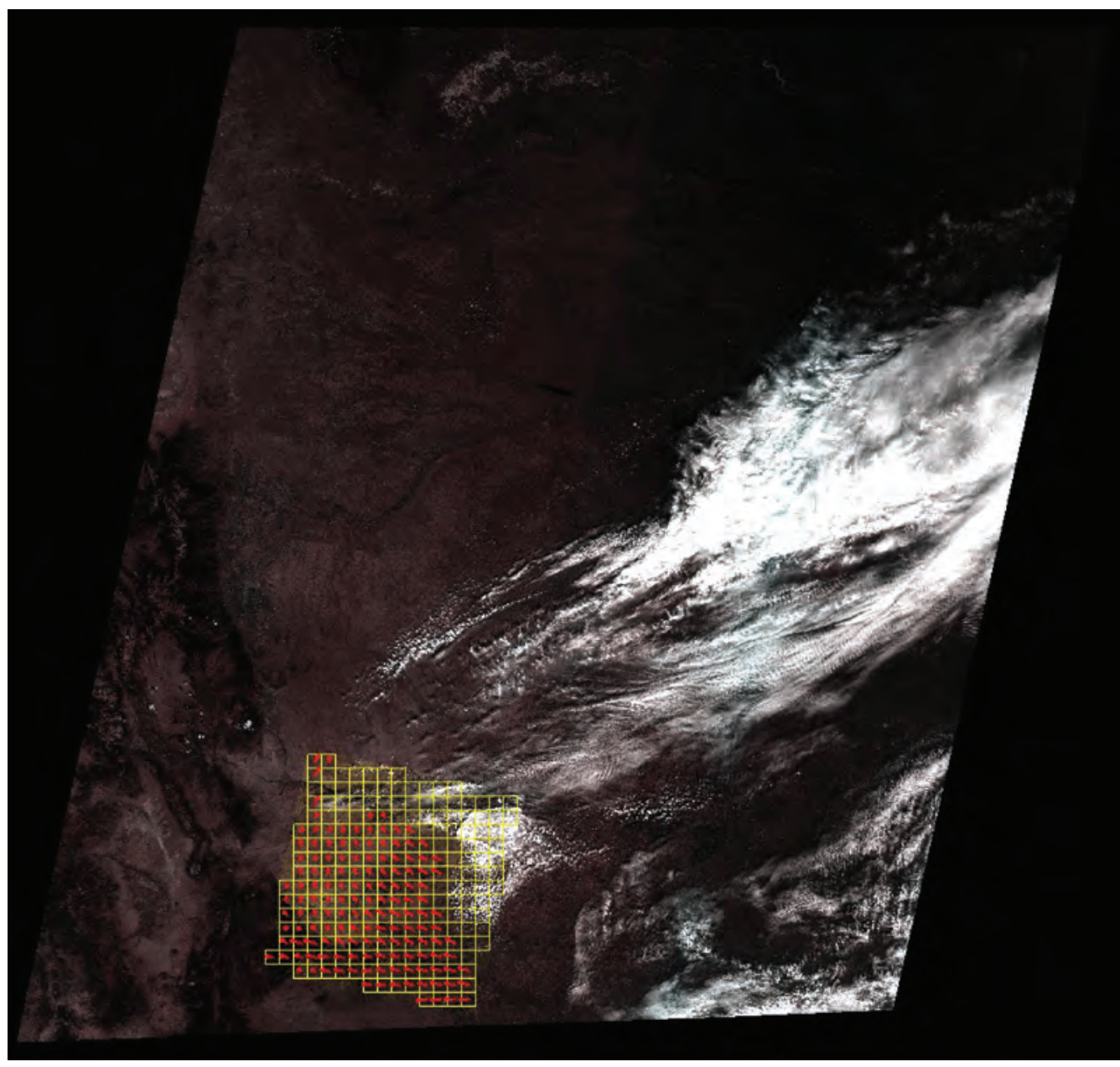

\section{EXPLANATION}

$\longrightarrow$ Easting and northing error Grid

Figure 8. Relative geometric error comparison for Landsat 8 Operational Land Imager and Resourcesat-2 Advanced Wide Field Sensor for Colorado. 

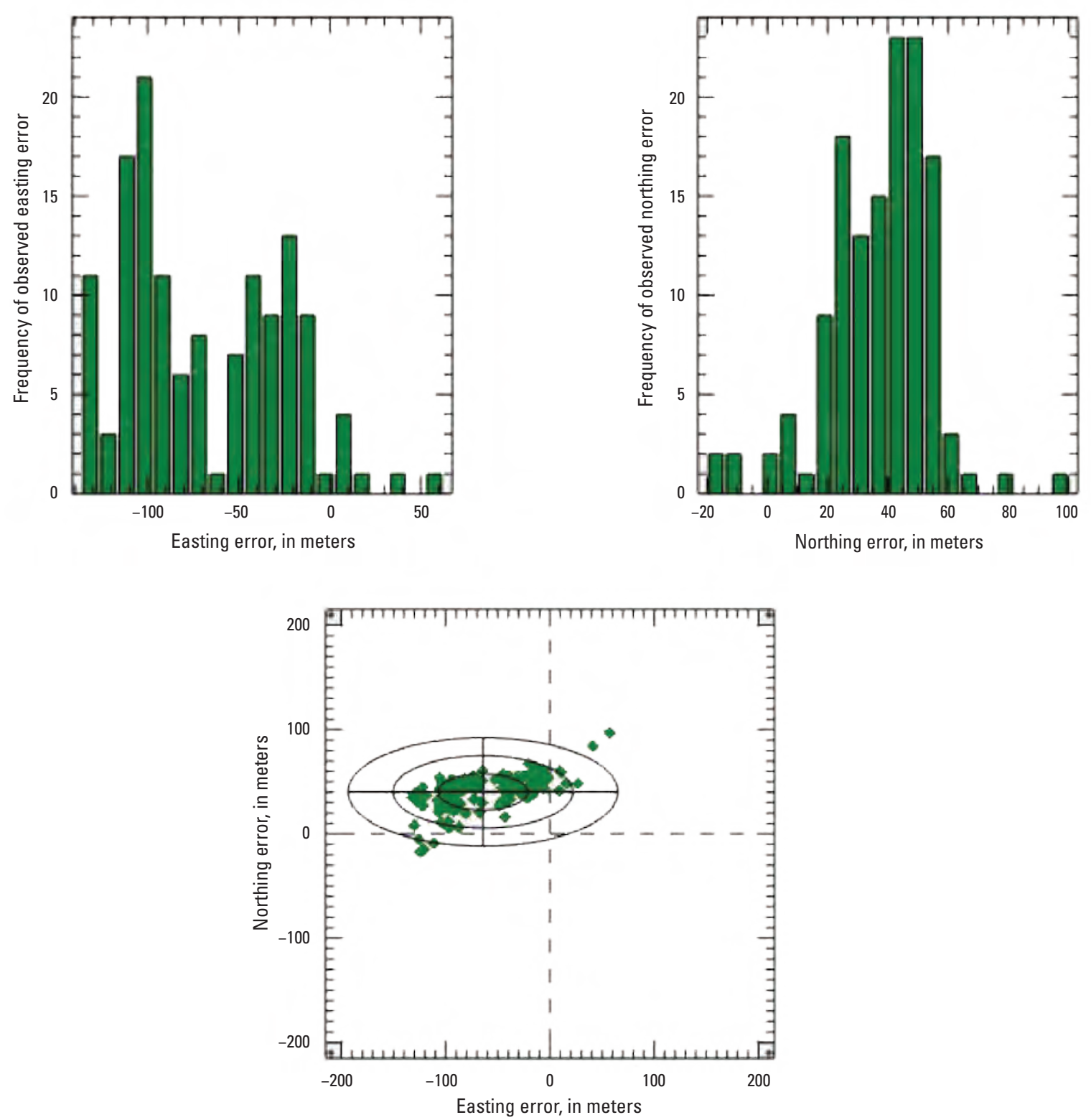

Figure 9. Relative geometric error histogram (upper) and error distribution (lower) for Colorado.

\section{Radiometric Performance}

For this analysis, cloud-free regions of interest were analyzed within three AWiFS and Landsat 8 OLI scene pairs using the EROSSC software. Raw digital number-to-radiance conversion coefficients were obtained from the Indian Space Research Organisation. The scatterplot (fig. 10) is drawn in a way that the $\mathrm{x}$-axis is the reference sensor and the $\mathrm{y}$-axis is the comparison sensor. The linear regression, thus, represents Top of Atmosphere reflectance relative to that of the reference sensor. Ideally, slope should be near unity and the offset should be near zero. For instance, if the slope is greater than unity, that means the comparison sensor has a tendency to overestimate Top of Atmosphere reflectance compared to the reference sensor.

Top of Atmosphere reflectance comparison results are listed in table 6. A band-by-band graphical comparison between the AWiFS image over Fargo, N. Dak., when compared against the corresponding Landsat 8 OLI band is shown in figure 10 . 


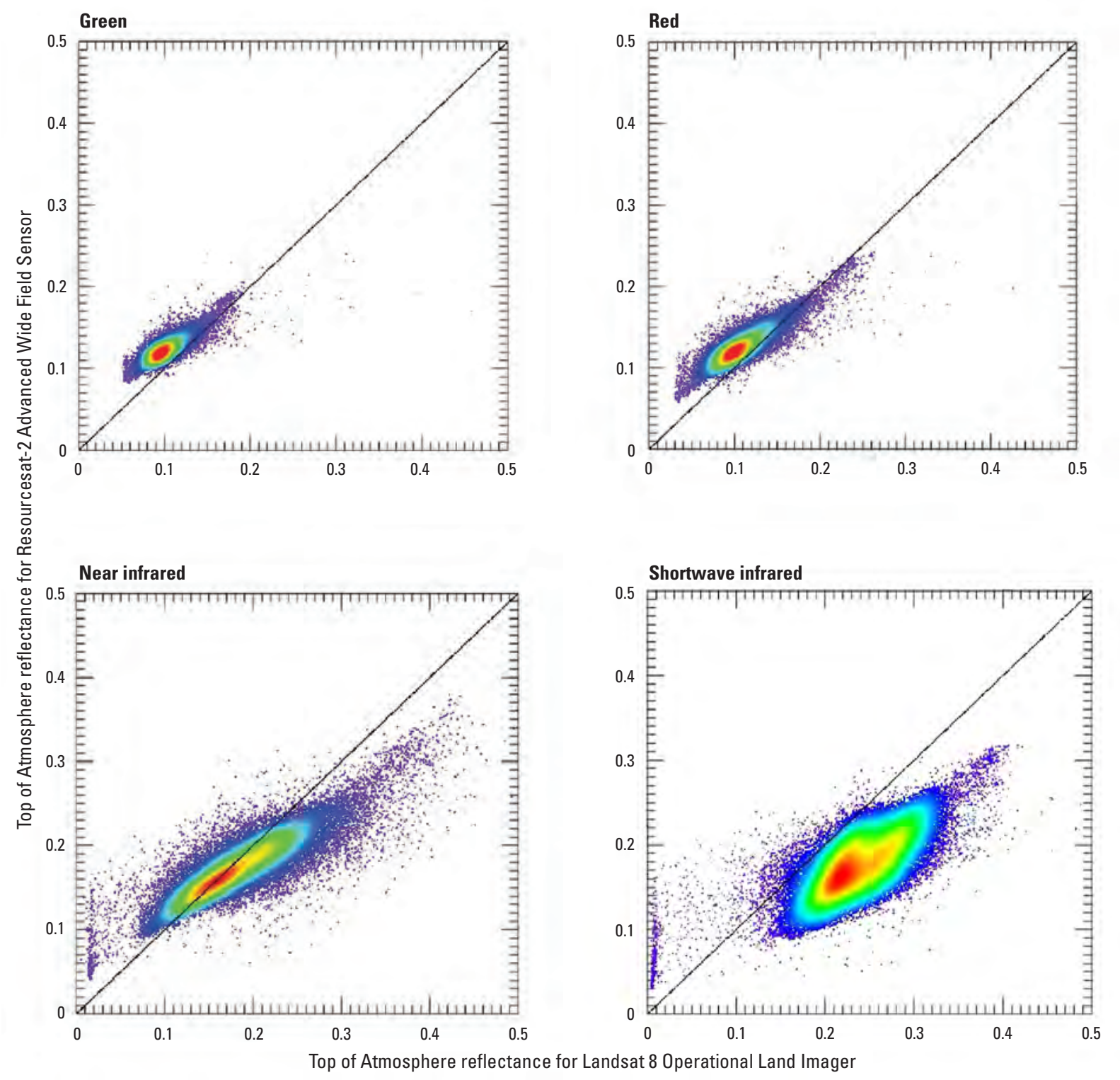

Figure 10. Top of Atmosphere reflectance comparison for Landsat 80 perational Land Imager and Resourcesat-2 Advanced Wide Field Sensor for Fargo, North Dakota.

\section{Spatial Performance}

For this analysis, edge spread, and line spread functions were calculated using the EROSSC software, with resulting relative edge response, full width at half maximum, and modulation transfer function at Nyquist frequency analysis output, as listed in table 7. The area selected within the Fargo, N. Dak., scene for spatial analysis is shown in figure 11. For spatial analysis, we usually prefer to select edges along human-made features; however, at the Resourcesat-2 AWiFS scale, only agricultural fields were large enough and had fairly straight edges. Therefore, we decided to look at agricultural fields and selected a bare field that was spectrally different in all four bands compared to the adjacent field. The yellow box in figure 11 shows the edge transect region of interest.

The band 2 (green) results are shown in figures 12 and 13. In figure 12, the dotted lines with diamond symbols are the raw transects. The green line is the middle transect, where the red dots are the region of the curve that is used for alignment. The lower plot in figure 12 is the aligned curve, and the green line represents the edge spread function. In the upper plot in figure 13, the white curve is the edge spread function, and the red line segment shows the relative edge response; the green curve is the line spread function, and the horizontal white line segment represents the full width at half maximum. 
Table 6. Top of Atmosphere reflectance comparison of Resourcesat-2 Advanced Wide Field Sensor against Landsat 8 Operational Land Imager.

[ID, identifier; B, band; \%, percent; $R^{2}$, coefficient of determination]

\begin{tabular}{|c|c|c|c|c|c|}
\hline Scene ID & Statistics & B2 & B3 & B4 & B5 \\
\hline \multirow{4}{*}{$\begin{array}{l}\text { R2AWF10212018267035_L1TLC08 } \\
\text { L1TP_030027_20181021_20200830_02_T1 } \\
\text { (Fargo, North Dakota) }\end{array}$} & Uncertainty (\%) & 8.490 & 12.050 & 16.620 & 14.230 \\
\hline & $R^{2}$ & 0.772 & 0.789 & 0.763 & 0.490 \\
\hline & Radical offset & 0.065 & 0.065 & 0.083 & -0.065 \\
\hline & Radical slope & 0.806 & 0.786 & 0.712 & 1.056 \\
\hline \multirow{4}{*}{$\begin{array}{l}\text { R2AWF10062019264041_L1TLC08_- } \\
\text { L1TP_032034_20191006_20200825_02_T1 } \\
\text { (Colorado) }\end{array}$} & Uncertainty (\%) & 7.430 & 10.460 & 8.990 & 11.230 \\
\hline & $R^{2}$ & 0.752 & 0.727 & 0.564 & 0.642 \\
\hline & Radical offset & 0.049 & 0.049 & 0.021 & 0.042 \\
\hline & Radical slope & 0.907 & 0.886 & 0.912 & 0.761 \\
\hline \multirow{4}{*}{$\begin{array}{l}\text { R2AWF07062018260042_L1TLC08_- } \\
\text { L1TP_033032_20180706_20200831_02_T1 } \\
\text { (New Mexico) }\end{array}$} & Uncertainty (\%) & 10.250 & 14.330 & 10.820 & 15.180 \\
\hline & $R^{2}$ & 0.752 & 0.796 & 0.787 & 0.632 \\
\hline & Radical offset & 0.043 & 0.031 & 0.040 & 0.031 \\
\hline & Radical slope & 0.746 & 0.741 & 0.708 & 0.652 \\
\hline
\end{tabular}

Table 7. Spatial performance of Resourcesat-2 Advanced Wide Field Sensor.

[RER, relative edge response; FWHM, full width at half maximum; MTF, modulation transfer function; NIR, near infrared; SWIR, shortwave infrared]

\begin{tabular}{lccc}
\hline \multicolumn{1}{c}{ Spatial analysis } & RER & $\begin{array}{c}\text { FWHM } \\
\text { (pixels) }\end{array}$ & MTF at Nyquist \\
\hline Band 2-green & 0.40 & 2.61 & 0.014 \\
Band 3-red & 0.38 & 2.65 & 0.006 \\
Band 4-NIR & 0.35 & 2.89 & 0.008 \\
Band 5-SWIR & 0.35 & 2.85 & 0.011 \\
\hline
\end{tabular}




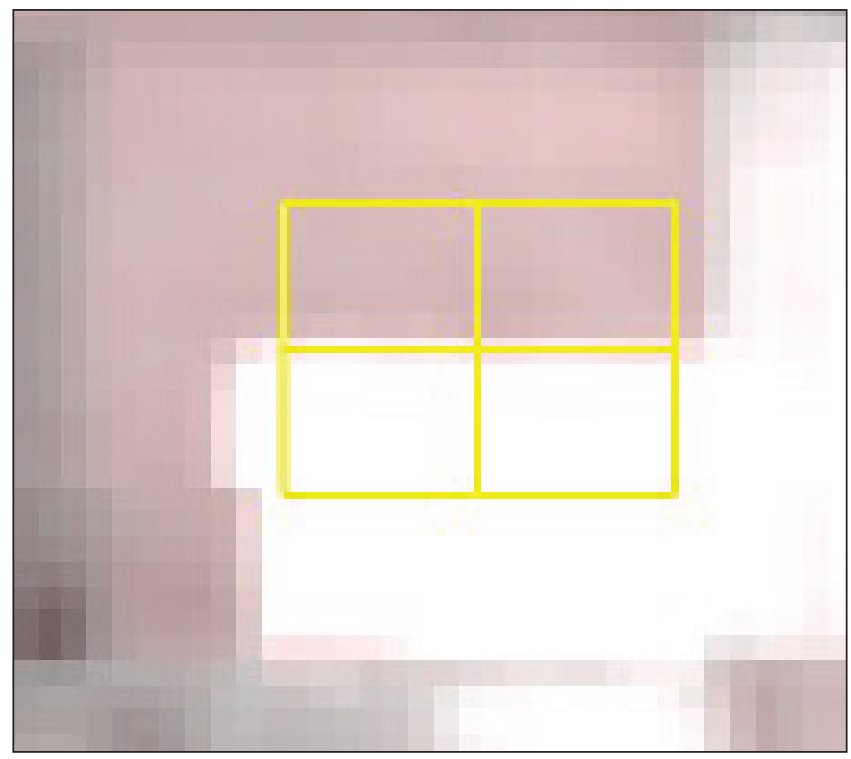

EXPLANATION

Edge transect region of interest

Figure 11. Resourcesat-2 Advanced Wide Field Sensor image region of interest selected for spatial analysis (Fargo, North Dakota).

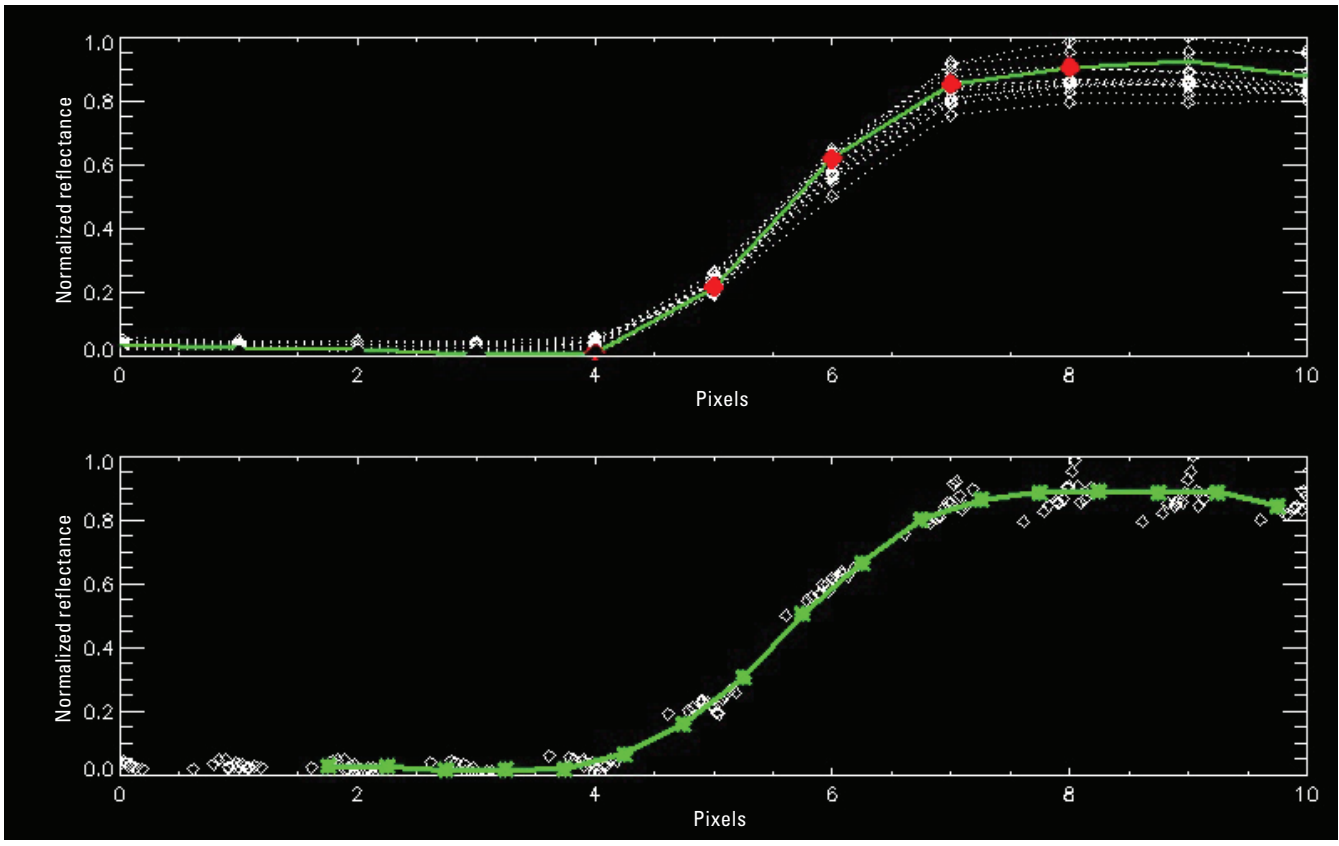

EXPLANATION

Middle transect

Raw transect

Region of the curve used for alignment

\section{EXPLANATION}

- Edge spread function

$\Delta$ Aligned transect

Figure 12. Band 2 (green) raw edge transects (upper) and aligned transects (lower). 

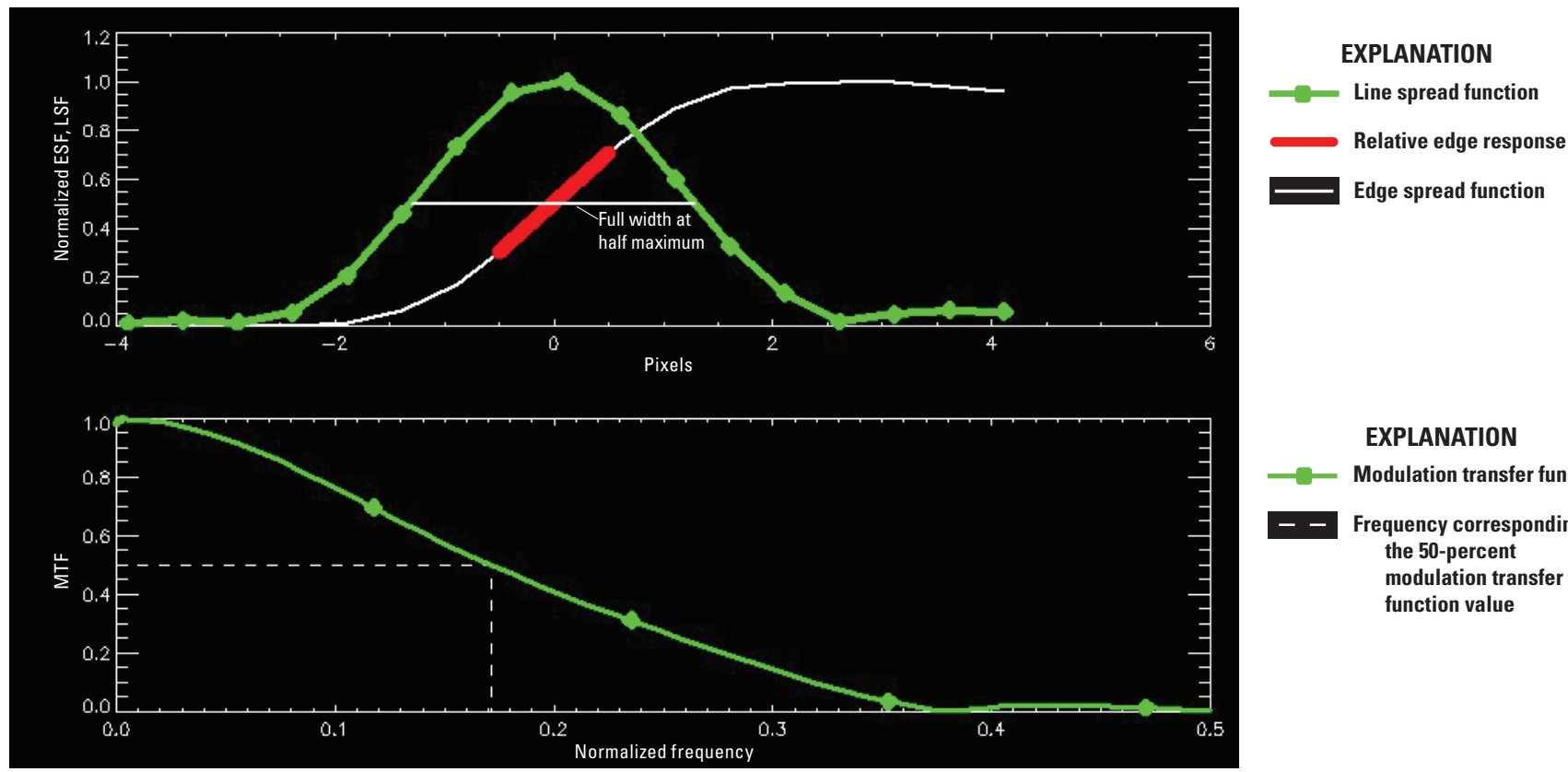

\section{EXPLANATION}

- Modulation transfer function

- - Frequency corresponding to the 50-percent modulation transfer function value

Figure 13. Band 2 (green) edge spread function (ESF) and line spread function (LSF; upper) and modulation transfer function (MTF; lower).
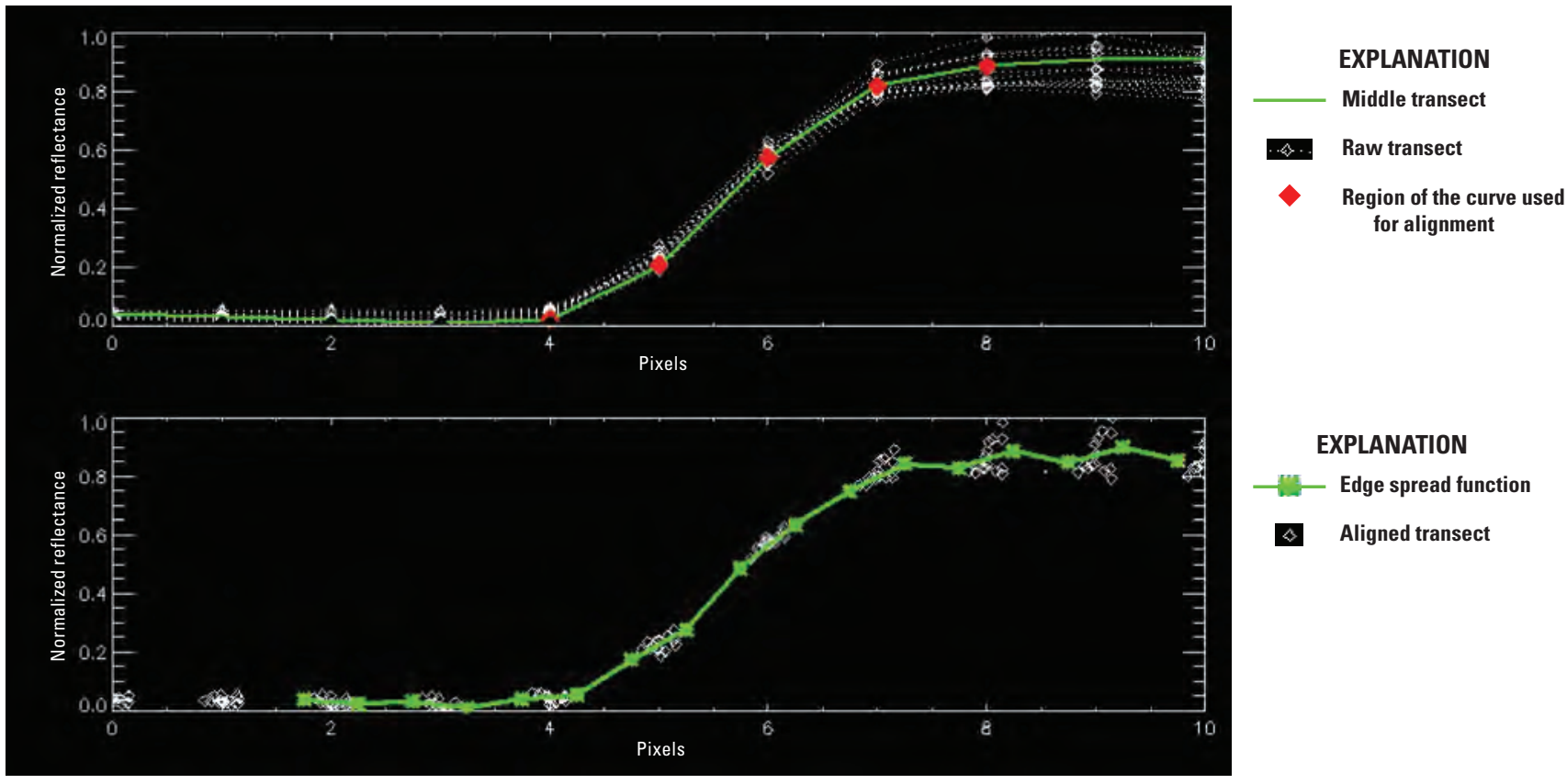

Figure 14. Band 3 (red) raw edge transects (upper) and aligned transects (lower).

The lower plot in figure 13 is the modulation transfer function up to Nyquist frequency (0.5), and the dashed line shows the frequency corresponding to the 50-percent modulation transfer function value.
The results for band 3 (red) are shown in figures 14 and 15. The results for band 4 (near infrared) are shown in figures 16 and 17. The results for band 5 (shortwave infrared) are shown in figures 18 and 19. 


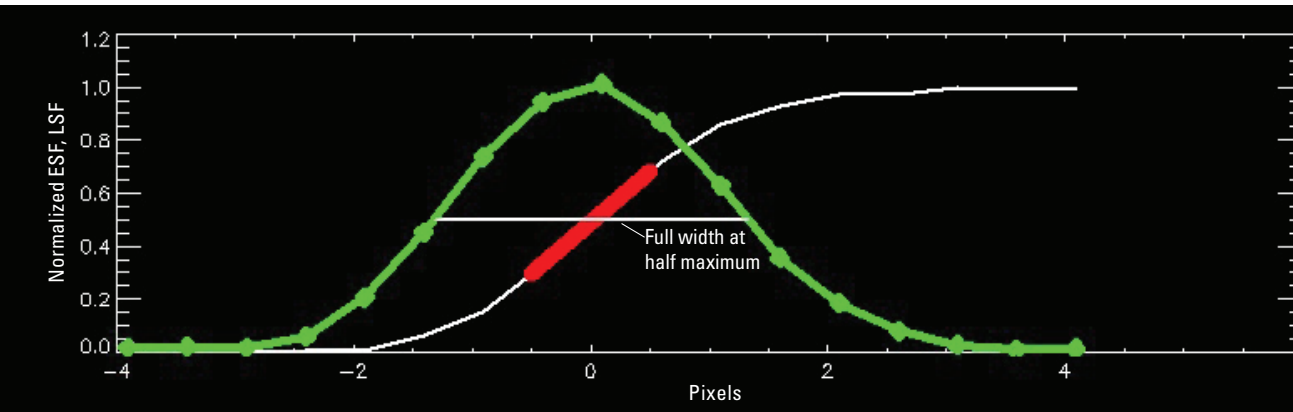

\section{EXPLANATION \\ - Line spread function \\ Relative edge response \\ Edge spread function}

\section{EXPLANATION}

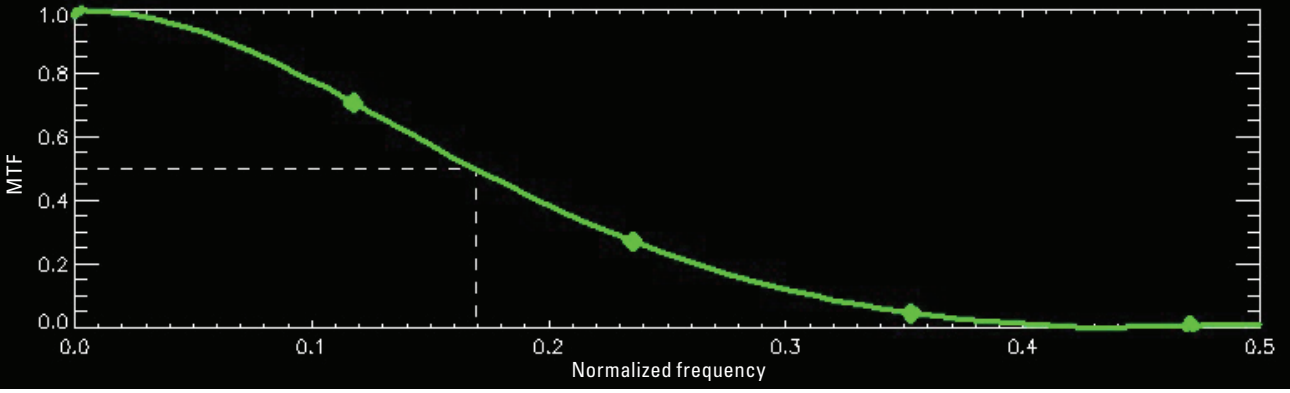

- Modulation transfer functio

- - Frequency corresponding to the 50-percent modulation transfer

function value

Figure 15. Band 3 (red) edge spread function (ESF) and line spread function (LSF; upper) and modulation transfer function (MTF; lower).

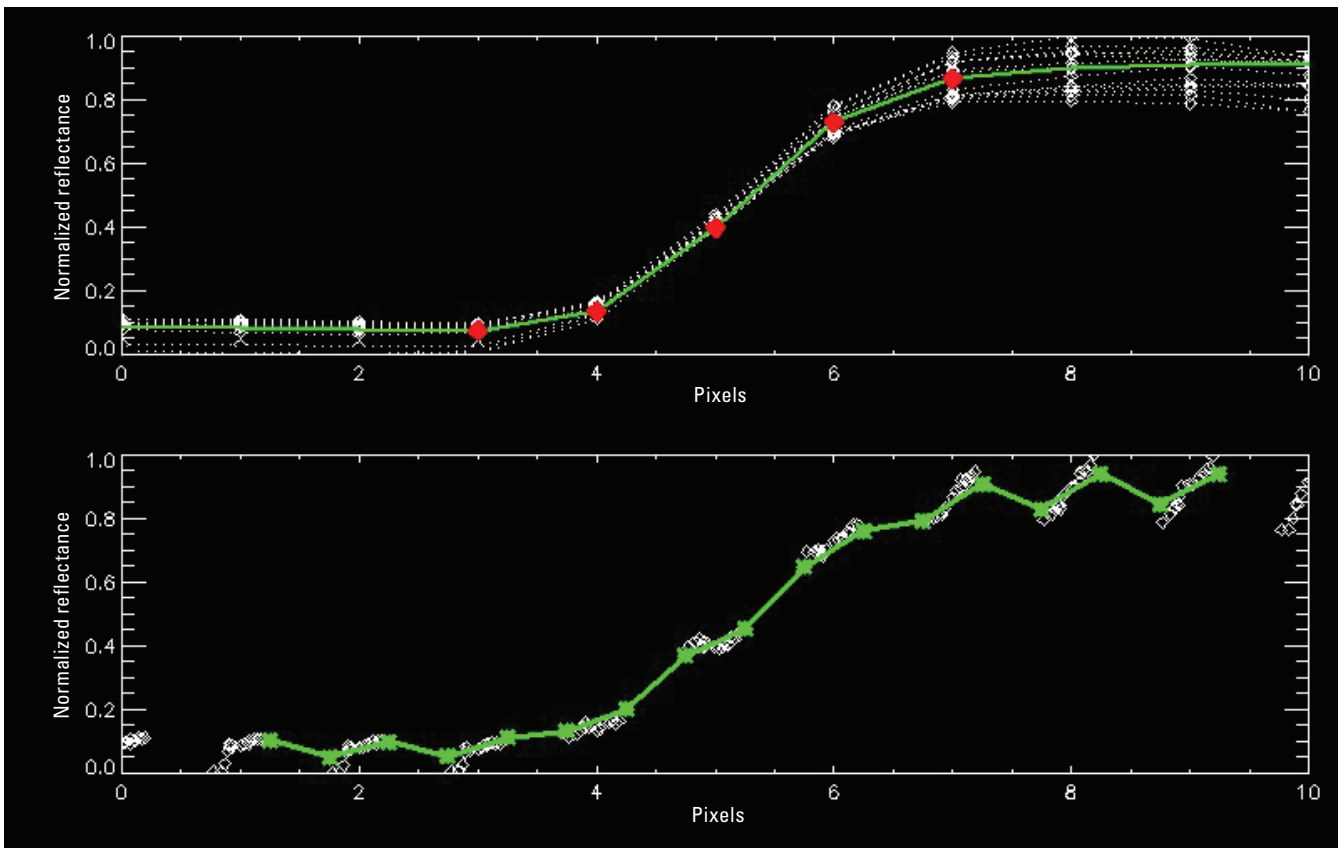

\section{EXPLANATION}

Middle transect

\section{Raw transect}

Region of the curve used for alignment

\section{EXPLANATION}

Edge spread function

Figure 16. Band 4 (near infrared) raw edge transects (upper) and aligned transects (lower). 


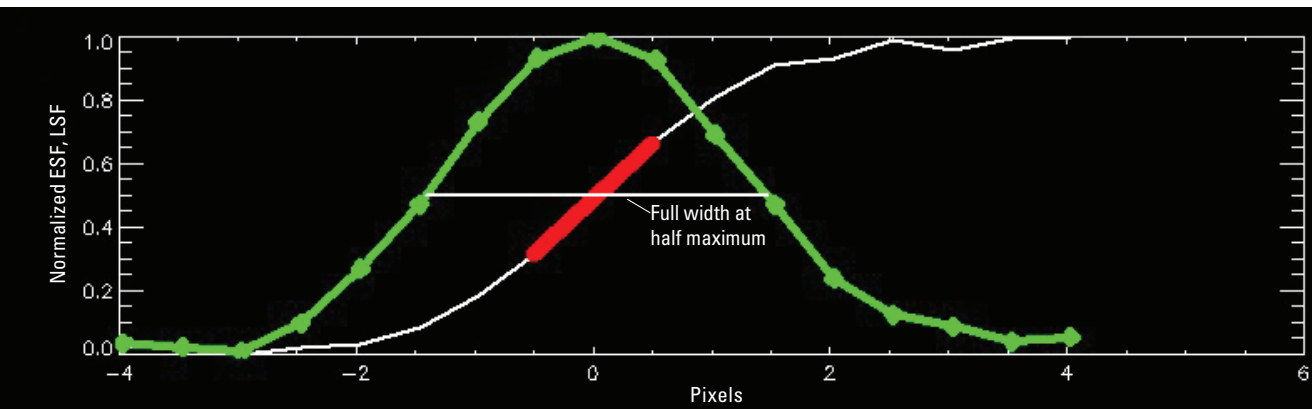

\section{EXPLANATION \\ - Line spread function \\ Relative edge response \\ Edge spread function}

\section{EXPLANATION}

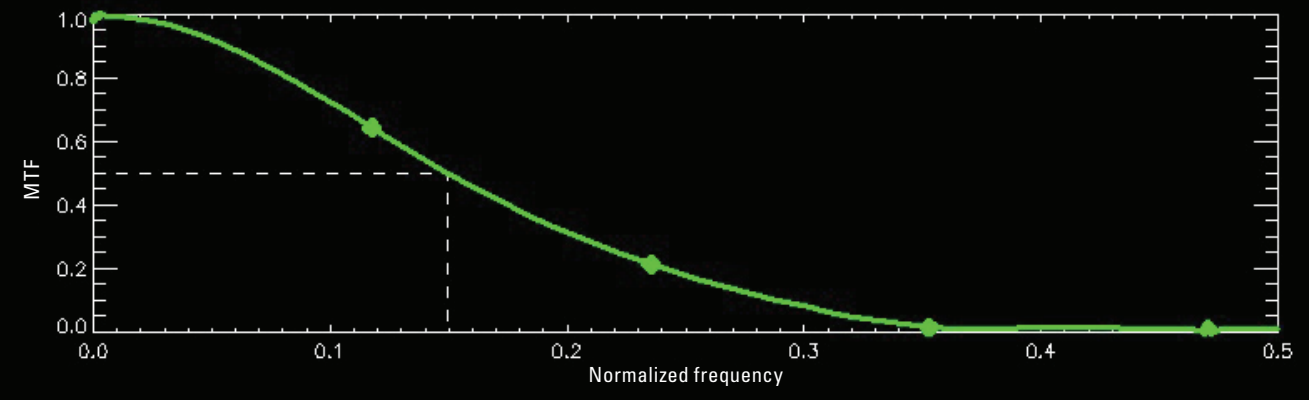

- Modulation transfer function

- - Frequency corresponding to the 50-percent

modulation transfer function value

Figure 17. Band 4 (near infrared) edge spread function (ESF) and line spread function (LSF; upper) and modulation transfer function (MTF; lower).

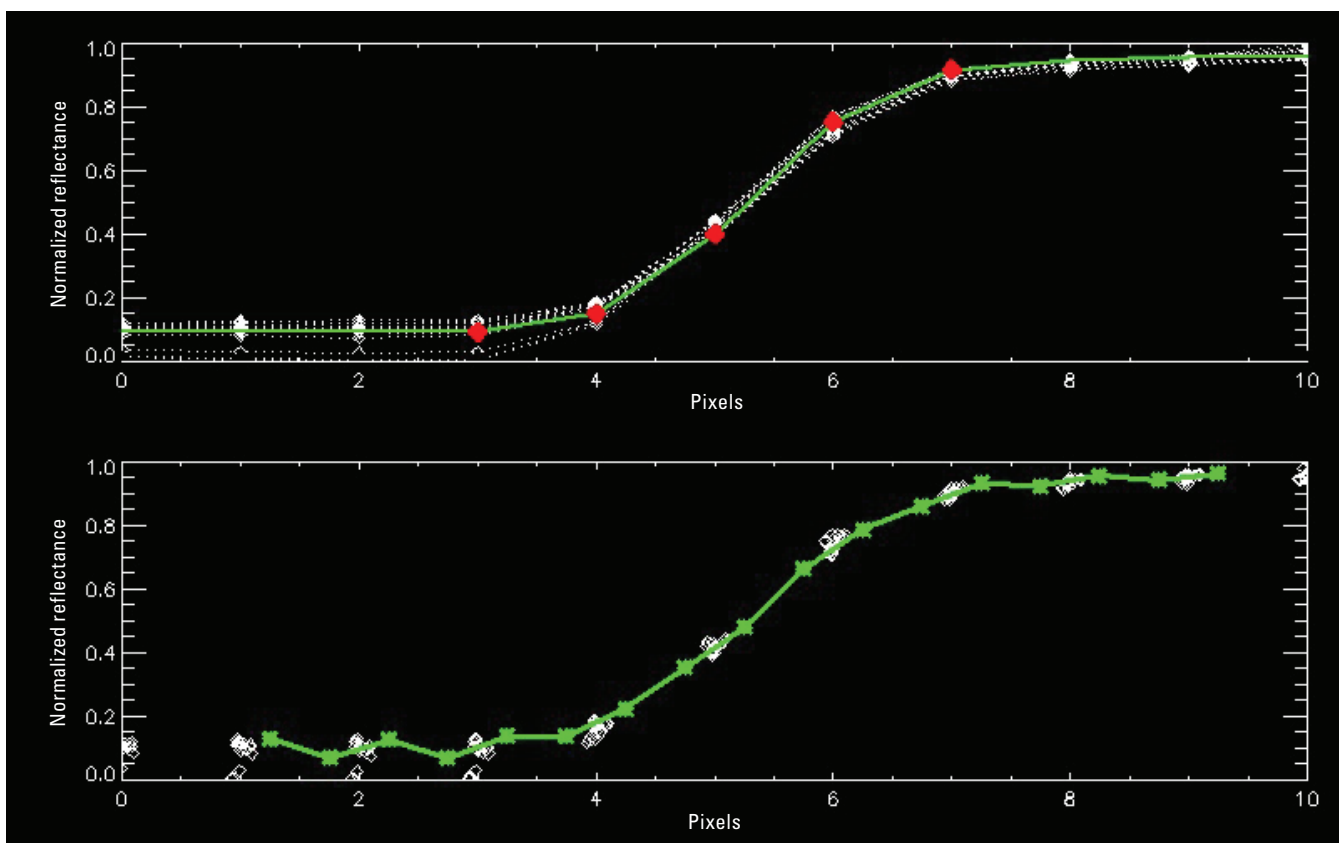

\section{EXPLANATION}

Middle transect

2. Raw transect

Region of the curve used for alignment

\section{EXPLANATION}

- Edge spread function

$\Delta$ Aligned transect

Figure 18. Band 5 (shortwave infrared) raw edge transects (upper) and aligned transects (lower). 


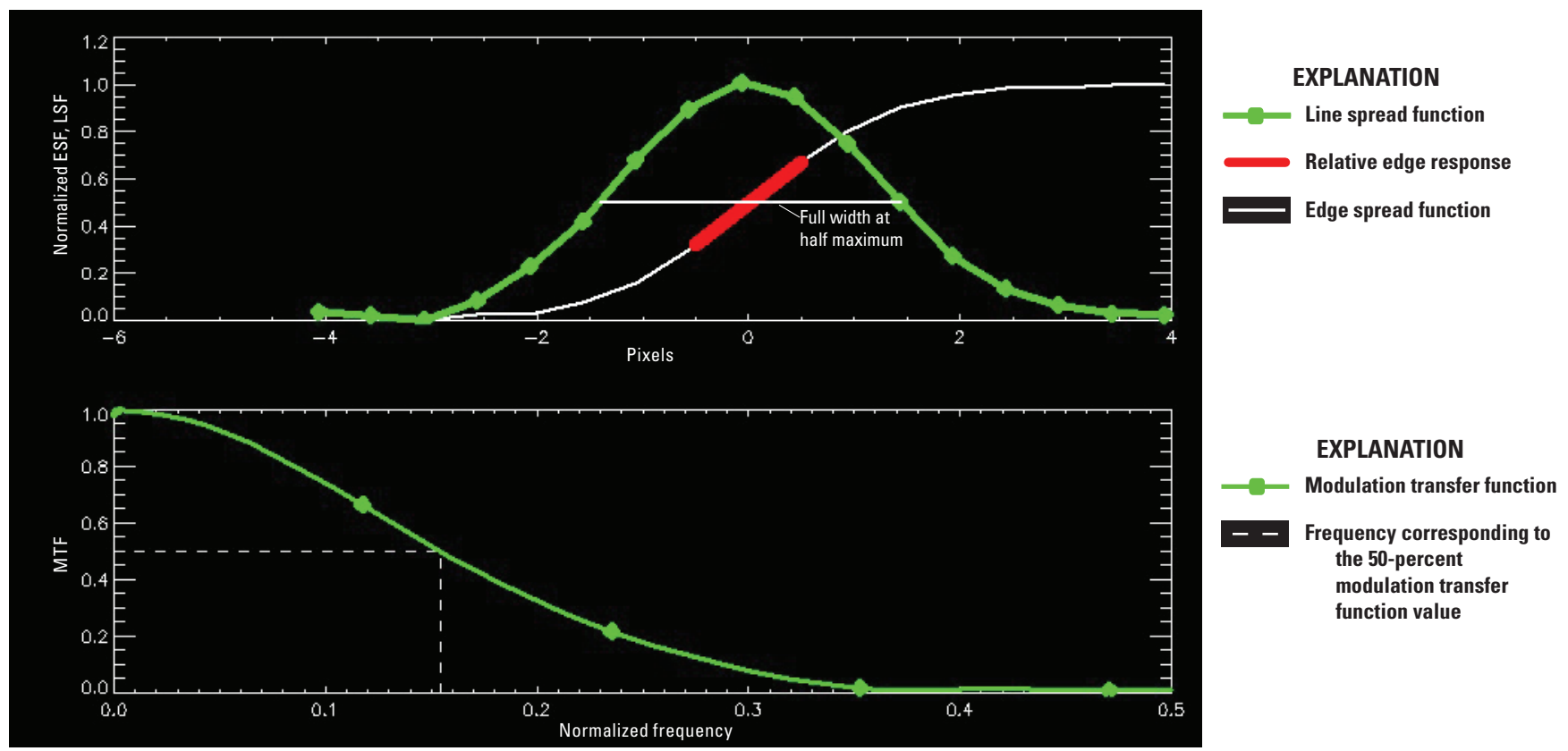

Figure 19. Band 5 (shortwave infrared) edge spread function (ESF) and line spread function (LSF; upper) and modulation transfer function (MTF; lower). 


\section{Summary and Conclusions}

This report summarizes the sensor performance of the Resourcesat-2 Advanced Wide Field Sensor (AWiFS) system based on the U.S. Geological Survey Earth Resources Observation and Science Cal/Val Center of Excellence (ECCOE) system characterization process. In summary, we have determined that this sensor provides an interior geometric performance in the range of $-16.080(-0.268$ pixel $)$ to 35.520 meters $(\mathrm{m} ; 0.592$ pixel) in easting and -25.680 $(-0.428$ pixel $)$ to $23.400 \mathrm{~m}$ ( 0.390 pixel $)$ in northing in bandto-band registration, an exterior geometric error of -64.262 $(-1.071$ pixels $)$ to $-19.059 \mathrm{~m}(-0.318$ pixel $)$ in easting and -29.028 ( -0.484 pixel) to $41.249 \mathrm{~m}(0.687$ pixel) in northing offset in comparison to the Landsat 8 Operational Land Imager, a radiometric performance in the range of -0.065 to 0.083 in offset and 0.652 to 1.056 in slope, and a spatial performance in the range of 2.61-2.89 pixels for full width at half maximum, with a modulation transfer function at a Nyquist frequency in the range of 0.006-0.014.

In conclusion, the team has completed an ECCOE standardized system characterization of the Resourcesat-2 AWiFS sensing system. Although the team followed characterization procedures that are standardized across the many sensors and sensing systems under evaluation, these procedures are customized to fit the individual sensor as was done with AWiFS. The team has acquired the data, defined proper testing methodologies, carried out comparative tests against specific references, recorded measurements, completed data analyses, and quantified sensor performance accordingly. The team also endeavored to retain all data, measurements, and methods. This is key to ensure that all data and measurements are archived and accessible and that the performance results are reproducible.

The ECCOE project and associated Joint Agency Commercial Imagery Evaluation partners are always interested in reviewing sensor and remote sensing application assessments and would like to see and discuss information on similar data and product assessments and reviews. If you would like to discuss system characterization with the U.S. Geological Survey ECCOE and (or) the Joint Agency Commercial Imagery Evaluation team, please email us at eccoe@usgs.gov.

\section{Selected References}

Indian Space Research Organisation, 2021, Resourcesat-2: Indian Space Research Organisation web page, accessed June 2021 at https://www.isro.gov.in/Spacecraft/ resourcesat-2.

Ramaseri Chandra, S.N., Christopherson, J.B., and Casey, K.A., 2020, 2020 Joint Agency Commercial Imagery Evaluation-Remote sensing satellite compendium: U.S. Geological Survey Circular 1468 (ver. 1.1, October 2020), 253 p. [Also available at https://doi.org/10.3133/cir1468.] [Supersedes USGS Circular 1455.]

U.S. Geological Survey, 2020a, EROS CalVal Center of Excellence (ECCOE): U.S. Geological Survey web page, accessed June 2021 at https://www.usgs.gov/core-sciencesystems/eros/calval.

U.S. Geological Survey, 2020b, EROS CalVal Center of Excellence (ECCOE) - JACIE: U.S. Geological Survey web page, accessed June 2021 at https://www.usgs.gov/ core-science-systems/eros/calval/jacie?qt-science_support_ page_related_con=3\#qt-science_support_page_related_con.

U.S. Geological Survey, 2020c, Landsat missions-Glossary and acronyms: U.S. Geological Survey web page, accessed June 2021 at https://www.usgs.gov/core-science-systems/ nli/landsat/glossary-and-acronyms. 
For more information about this publication, contact:

Director, USGS Earth Resources Observation and Science Center 47914 252nd Street

Sioux Falls, SD 57198

605-594-6151

For additional information, visit: https://www.usgs.gov/centers/eros

Publishing support provided by the

Rolla Publishing Service Center 


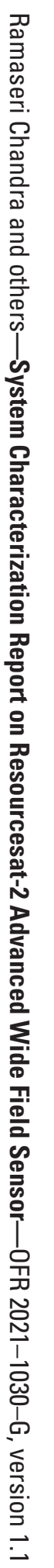

